\title{
The Infrared Spectra of Matrix Isolated Uranium Oxide Species*
}

\author{
S. Abramowitz and N. Acquista \\ Institute for Materials Research, National Bureau of Standards, Washington, D.C. 20234
}

(February 13, 1974)

\begin{abstract}
The infrared spectra of matrix isolated products of the interaction of uranium and oxygen have been investigated at high temperatures. By use of collateral available data on the various uranium oxide species, plus employment of oxygen 16 and 18 isotopes, peak assignments were verified for many of the neutral metal oxide species.
\end{abstract}

Key words: Infrared spectra; mass spectrophotometry; matrix isolated; oxides of uranium.

\section{Introduction}

The infrared spectra of matrix isolated uranium oxides have been studied by several investigators [1-6]. ${ }^{1}$ Although the spectra were similar, these workers differed in their interpretation and assignment of the observed bands. In particular, Abramowitz et al. [1, 2]; and Leary et al. [3]; assigned two absorption bands at 873 and $776 \mathrm{~cm}^{-1}$ to $\mathrm{UO}_{2}$ and UO while Carstens et al. [4], and Gabelnick et al. $[5,6]$, assigned the features at 776 and $820 \mathrm{~cm}^{-1}$ to $\mathrm{UO}_{2}$ and $\mathrm{UO}$ respectively. All workers with the exception of Carstens et al. [4] used oxygen isotopically enriched urania to support their assignments. The uranium oxides were prepared by vaporization of the solid oxides from Knudsen effusion cells [1-3, 5, 6]. Carstens et al. prepared uranium oxides by chemically sputtering a uranium metal cathode with an argonoxygen mixture by means of a discharge in a hollow cathode device [4]. By the latter technique, it was possible to monitor the $\mathrm{UO} / \mathrm{UO}_{2} / \mathrm{UO}_{3}$ ratio by changing the oxygen/argon concentration.

It has been shown that the reaction of $\mathrm{U}(\mathrm{g})$, and oxygen species $\mathrm{O}, \mathrm{O}_{2}$, and $\mathrm{O}_{3}$ yield the ionic species $\mathrm{UO}^{+}$and $\mathrm{UO}_{2}^{+}$in addition to the neutral products. Because of the uncertainty inherent in the sputtering technique as to the state of the oxygen species and/or uranium atoms it was felt worthwhile to perform these experiments with well characterized uranium beams obtainable from Knudsen cells. The reaction products were deposited on gold plated OFHC copper discs so that the ionic species that are produced in these reactions will be neutralized. The products of the reaction of an uranium beam with varying dilutions of argon-oxygen and argon-nitrous oxide mixtures were studied. In this way one could in principle produce different relative concentrations of UO,

\footnotetext{
*Work supported in part by the Defense Nuclear Agency, Washington, D.C. 20305. 'Figures in brackets indicate the literature references at the end of this paper.
}

$\mathrm{UO}_{2}$, and $\mathrm{UO}_{3}$ by varying the $\mathrm{O} / \mathrm{U}$ ratio. In addition, the matrix-mixtures could be passed through a microwave discharge to determine what effect an increase in $\mathrm{O}$ and $\mathrm{O}_{3}$ species would have on the uranium oxides spectra.

\section{Experimental Procedure}

The apparatus and procedure used to prepare matrices have been described [1]. Unlike the sputtering method used by Carstens et al. [4], the uranium atoms were produced by vaporization of the metal from a single crystal tungsten cup placed inside a polycrystalline tungsten crucible capped with a 0.005 in tantalum foil with a $1 \mathrm{~mm}$ orifice. The temperature of the Knudsen crucible was measured with a W 25 percent Re versus W 3 percent Re thermocouple inserted in an 0.040 in hole drilled up the side of the cell. An electron beam furnace mounted directly beneath the deposition plate was used to vaporize the uranium to temperatures of about $1950{ }^{\circ} \mathrm{C}$. Matrices were formed in $1-2 \mathrm{~h}$. The matrix jet was $45^{\circ}$ relative to the effusing atom beam. Beams of $\mathrm{O}, \mathrm{O}_{2}, \mathrm{O}_{3}$ and $\mathrm{N}_{2} \mathrm{O}$ diluted in argon were codeposited with the uranium atoms onto a gold plated OFHC copper disc mounted in the crystal holder of an Air Products closed cycle helium refrigerator [7] operated at 10 to $15{ }^{\circ} \mathrm{K}$. Temperatures of the deposition plate were measured with a hydrogen bulb thermometer and a gold-iron versus chromel thermocouple. Deposition on a metallic surface was chosen so as that ionic species which are produced by these reactions will be neutralized [8]. Some previous experiments, as yet unpublished, have suggested the presence of trapped ionic species in an argon matrix.

The uranium used in these experiments was an NBS standard sample, while the argon was of research grade purity. The oxygen, nitrous oxide and isotopic mixtures of oxygen were obtained from com- 
mercial sources and used without further purification.

The concentration of uranium oxides in argon was estimated using the standard effusion formula and the geometry of the system. During deposition the crucible was maintained at 1900 to $2100{ }^{\circ} \mathrm{C}$ to give a uranium vapor pressure in the range of 0.001 to 0.003 torr [9]. The rare-gas to oxygen mixture whose concentration varied from 1000 to 50 was deposited at the rate of $3-6 \mathrm{mmol} / \mathrm{h}$. Using this data, the concentrations of rare gas to total uranium oxides were estimated to be from 5000 to 50,000 .

Infrared spectra were observed using a Perkin Elmer Model 99G [7] with a grating blazed for $12 \mu \mathrm{m}$. An interference filter was used to block out the higher order radiation. Atmospheric water and ammonia lines were used to calibrate the spectra. It is estimated that the wave numbers are accurate to \pm 0.5 $\mathrm{cm}^{-1}$ in the $700-900 \mathrm{~cm}^{-1}$ region.

\section{Experimental Results}

Representative infrared spectra obtained by reacting uranium atoms with varying concentration of argon-oxygen solutions are shown in figure 1 . At the highest dilution of oxygen used $\left(\mathrm{Ar} / \mathrm{O}_{2}=1000\right)$ two features appear at 820 and $776 \mathrm{~cm}^{-1}$. These have been assigned to $\mathrm{UO}$ and $\mathrm{UO}_{2}$ respectively by Carstens et al. [4] and Gabelnick et al. [5, 6]. As the concentration of $\mathrm{O}_{2}$ is increased $\left(\mathrm{Ar} / \mathrm{O}_{2}=50\right)$, the intensity of the band at $776 \mathrm{~cm}^{-1}$ relative to the band at $820 \mathrm{~cm}^{-1}$ is increased. As the concentration is further increased, the $820 \mathrm{~cm}^{-1}$ feature disappears and new bands appear at 853 and $745 \mathrm{~cm}^{-1}$. These new features have been assigned to the two stretching modes of $\mathrm{UO}_{3}[4,6]$. Finally, in pure oxygen only features assignable to $\mathrm{UO}_{3}$ are observed. These results are shown in curves $\mathrm{a}, \mathrm{b}, \mathrm{c}$ in figure 1 .

In another series of experiments, $\mathrm{Ar} / \mathrm{O}_{2}$ was passed through a microwave discharge prior to reacting them with the uranium beam. The resulting ozone and oxygen atoms react with the uranium to produce a small increase of the $820 \mathrm{~cm}^{-1}$ peak relative to the $776 \mathrm{~cm}^{-1}$ band.
Figure 2 shows the spectra of the reaction products of uranium atoms with different mixtures of $\mathrm{Ar} / \mathrm{N}_{2} \mathrm{O}$ at cryogenic temperatures. The spectra show a similar concentration dependence as those obtained with $\mathrm{Ar} / \mathrm{O}_{2}$ mixtures, and the similar spectra. At the highest concentrations of $\mathrm{N}_{2} \mathrm{O}$ used $\left(\mathrm{Ar} / \mathrm{N}_{2} \mathrm{O}=50\right) \mathrm{UO}_{2}$ and $\mathrm{UO}_{3}$ peaks are much more intense than UO (curve a, fig. 2). At the lowest concentration used, the $820 \mathrm{~cm}^{-1}$ $\mathrm{UO}$, band, was more intense than the $776 \mathrm{~cm}^{-1}, \mathrm{UO}_{2}$ band. A significant increase in the $\mathrm{UO}$ feature is obtained by passing $\mathrm{Ar} / \mathrm{N}_{2} \mathrm{O}$ mixtures through a microwave discharge, producing oxygen atoms and nitrogen. Another peak at $804 \mathrm{~cm}^{-1}$ is comparable in intensity with UO (see fig. 2). The species responsible for this peak may be a uranium nitrogen species. However, more experiments are needed to elucidate this.

Further experiments were performed using $\mathrm{Ar} /{ }^{18} \mathrm{O}_{2}$ and a mixture of 2 parts ${ }^{16} \mathrm{O}^{18} \mathrm{O}$ to 1 part each of ${ }^{16} \mathrm{O}_{2}$ and ${ }^{18} \mathrm{O}_{2}$ also in argon. These experiments yield vibrational frequencies for mixed isotopes of $\mathrm{UO}_{2}$ and $\mathrm{UO}_{3}$. The results of these isotopic experiments are shown in figure 3. Curve " $b$ " is the spectrum obtained by reacting $\mathrm{Ar} /{ }^{18} \mathrm{O}_{2}(=100)$ with uranium atoms. The isotopic ${ }^{18} \mathrm{O}_{2}$ contains very little ${ }^{16} \mathrm{O}_{2}(\sim 1 \%)$ and this is reflected in the spectra by the absence of $\mathrm{U}^{16} \mathrm{O}$ at $820 \mathrm{~cm}^{-1}$ and $\mathrm{U}^{16} \mathrm{O}_{3}$ at $853 \mathrm{~cm}^{-1}$ and $745 \mathrm{~cm}^{-1}$. Therefore this spectrum shows bands due to ${ }^{18} \mathrm{O}_{2}$ and the mixed ${ }^{16,18} \mathrm{O}_{2}$. The band at $776 \mathrm{~cm}^{-1}$ is $\mathrm{U}^{18} \mathrm{O}$, while the band at $772 \mathrm{~cm}^{-1}$ is $\mathrm{U}^{16} \mathrm{O}^{18} \mathrm{O}$. The others peaks are due to isotopic $\mathrm{UO}_{3}$. Spectrum "a", where the single isotope ${ }^{16} \mathrm{O}_{2}$ is used, is included in figure 3 for comparison.

Curve "c" is representative of the spectra obtained when uranium atoms react with an isotopic mixture of $\mathrm{Ar} / \mathrm{O}_{2} \quad(=350)$ of $\left({ }^{16} \mathrm{O}_{2}: 2^{16} \mathrm{O}^{18} \mathrm{O}:{ }^{18} \mathrm{O}_{2}\right)$. All the isotopic variations of $\mathrm{UO}, \mathrm{UO}_{2}$ and $\mathrm{UO}_{3}$ are present in varying degrees of intensity. The band at $776 \mathrm{~cm}^{-1}$ is present, its intensity due to $\mathrm{U}^{18} \mathrm{O}$ and $\mathrm{U}^{16} \mathrm{O}_{2}$. Below this band, is the mixed isotope band $v_{3}$ at $772 \mathrm{~cm}^{-1}$, $\mathrm{U}^{16} \mathrm{O}^{18} \mathrm{O}$. The band at $728.8 \mathrm{~cm}^{-1}$, which is not present in spectrum " $a$ " or " $b$ " is the mixed isotopic $\mathrm{U}^{16} \mathrm{O}^{18} \mathrm{O}$ fundamental $v_{1}$ the symmetric stretch-

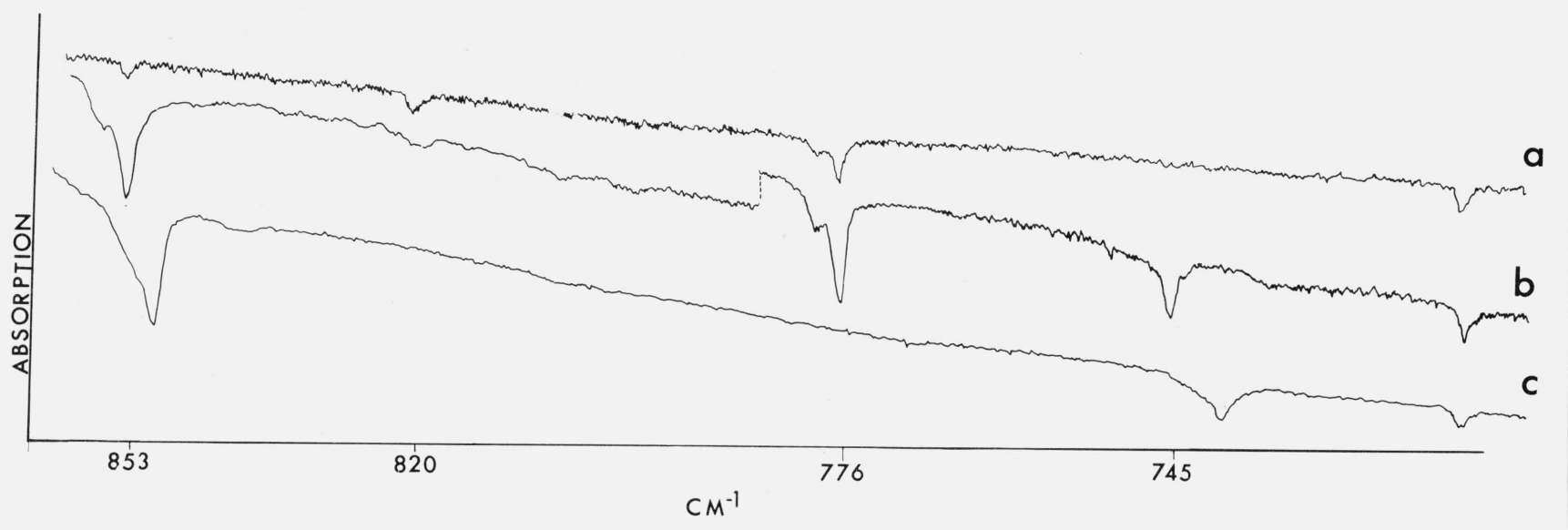

FIGURE 1. The infrared spectrum of uranium oxides in argon matrices. (Note $\mathrm{CO}_{2}$ at about $720 \mathrm{~cm}^{-1}$ in all spectra.)

(a) Uranium vapor reacted with $\mathrm{Ar} / \mathrm{O}_{2}=1000$

(b) Uranium vapor reacted with $\mathrm{Ar} / \mathrm{O}_{2}=50$

(c) Uranium vapor reacted with pure $\mathrm{O}_{2}$ 


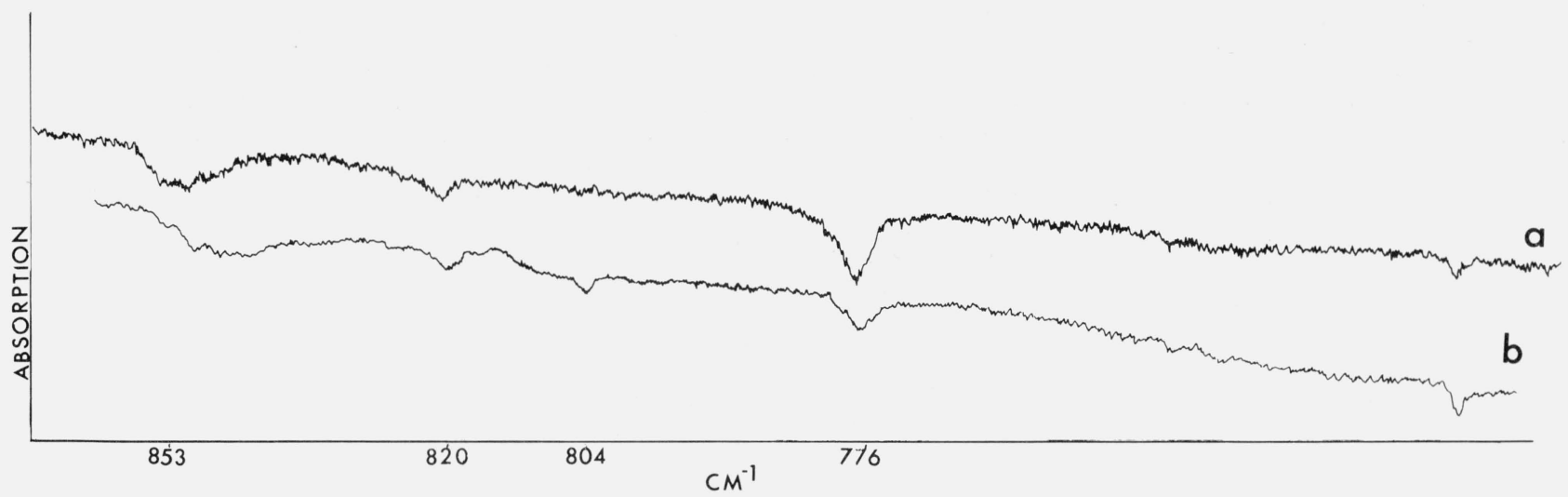

FIGURE 2. The infrared spectrum of uranium oxides in argon matrix.

(a) Uranium atoms reacted with $\mathrm{Ar} / \mathrm{N}_{2} \mathrm{O}=50$

(b) Uranium atoms reacted with $\mathrm{Ar} / \mathrm{N}_{2} \mathrm{O}=100$ passed through a microwave discharge

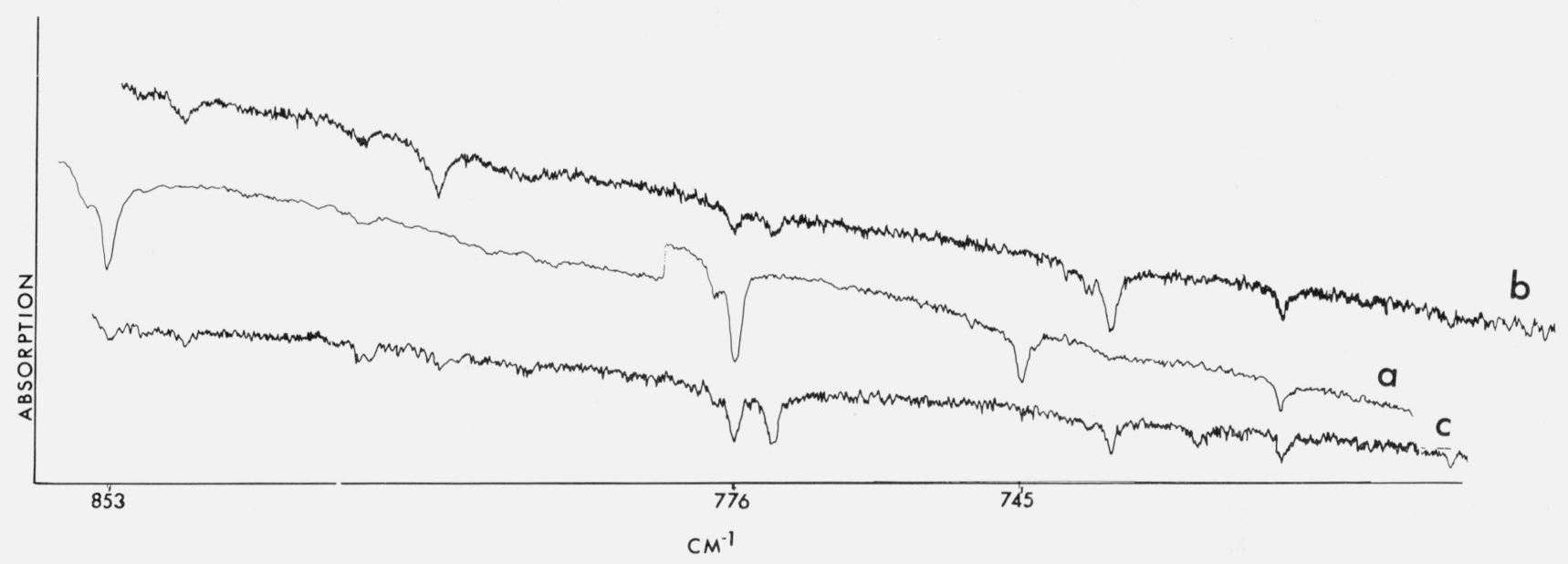

FIGURE 3. The infrared spectrum of uranium oxides in argon matrices.

(a) Spectrum obtained when uranium vapor reacts with $\mathrm{Ar} /{ }^{16} \mathrm{O}_{2}=50$

(b) Spectrum of $\mathrm{U}^{18} \mathrm{O}, \mathrm{U}^{18} \mathrm{O}_{2}$, and $\mathrm{U}^{18} \mathrm{O}^{18} \mathrm{O}$ obtained when uranium is codeposited with $\mathrm{Ar} /{ }^{18} \mathrm{O}_{2}=100$ (about $15 \%{ }^{16} \mathrm{O}^{18} \mathrm{O}$ in ${ }^{18} \mathrm{O}_{2}$ is present).

(c) Spectrum obtained when uranium vapor reacts with a mixture in argon of ${ }^{16} \mathrm{O}_{2},{ }^{16} \mathrm{O}^{18} \mathrm{O},{ }^{18} \mathrm{O}_{2}$ in ratio of $1: 2: 1 \quad(=350)$.

ing mode of $\mathrm{UO}_{2}$. This band is observed because it is now infrared active. In the symmetrical molecules $\mathrm{U}^{18} \mathrm{O}_{2}$ and $\mathrm{U}^{16} \mathrm{O}_{2}$. $\nu_{1}$ bands are infrared inactive. The other bands present in the mixed isotope experiment are due to $\mathrm{UO}_{3}$. Curve "c" shows the spectrum. It is clear from the above experiments that the same spectra are obtained by condensing the vapors over urania in argon and also by codepositing a uranium atom beam with an oxygen argon mixture. The bands are all listed in table 1 with their assignment together with Gabelnick's results $[4,5]$.

In a final experiment, the spectrum of the matrix isolated vapors above $\mathrm{UO}_{2}(\mathrm{~s})$ effusing from a single crystal tungsten cup (which in turn was placed inside of polycrystalline tungsten cell, covered with a tantalum foil with a $1 \mathrm{~mm}$ hole) was observed. Bands were observed at 853 and $776 \mathrm{~cm}^{-1}$ due to $\mathrm{UO}_{3}$ and $\mathrm{UO}_{2}$ but none at 873 and at $820 \mathrm{~cm}^{-1}$. It was apparent from this experiment and those involving reactions between uranium atoms and $\mathrm{O}_{2}$ molecules where no
TABLE 1. Observed bands and assignments of uranium oxides in argon matrices

\begin{tabular}{c|c|c}
\hline \hline Wave number & Wave number & Assignment \\
\hline $\mathrm{cm}^{-1 \mathrm{a}}$ & $\mathrm{cm}^{-1 \mathrm{~b}}$ & \\
819.6 & 820.0 & $\mathrm{U} 16 \mathrm{O}$ \\
776.1 & 776.1 & $\mathrm{U}^{18} \mathrm{O}$ \\
776.1 & 776.1 & $\mathrm{U}^{16} \mathrm{O}_{2}$ \\
737.2 & 737.1 & $\mathrm{U}^{18} \mathrm{O}_{2}$ \\
771.7 & 771.1 & $\mathrm{U}^{16} \mathrm{O}^{18} \mathrm{O}$ \\
728.8 & 828.4 & $\mathrm{U}^{16} \mathrm{O}^{18} \mathrm{O}$ \\
809.9 & 705.9 & $\mathrm{U}^{18} \mathrm{O}_{3}$ \\
705.2 & 852.5 & $\mathrm{U}^{18} \mathrm{O}_{3}$ \\
852.5 & 745.6 & $\mathrm{U}^{16} \mathrm{O}_{3}$ \\
745.4 & 847.5 & $\mathrm{U}^{16} \mathrm{O}_{3}$ \\
847.7 & 842.5 & \\
842.4 & 731.8 & $\mathrm{U}^{16,18} \mathrm{O}_{3}$ \\
731.9 & & $\mathrm{U}^{16,18} \mathrm{O}_{3}$ \\
720.5 & & $\mathrm{U}^{16,18} \mathrm{O}_{3}$ \\
804.2 & $\mathrm{CO} \mathrm{O}_{2}$ \\
\hline
\end{tabular}

a This work.

b Reference [5]. 
band was found at $873 \mathrm{~cm}^{-1}$ under any of our experimental conditions that this feature is not a uranium oxide band but some unknown impurity. Neither was UO observed in the matrix. To produce UO, it is necessary to prepare a mixture of uranium metal and urania and to equilibrate at $1900^{\circ} \mathrm{C}$ for several hours $[5,6]$. Our results are summarized in table 1 and the assignment is in accord with Gabelnick et al. and Carstens et al. [4-6].

In conclusion, we have observed the spectra of the products of the reactions of a well characterized uranium beam with various oxygen species. The results appear to indicate that uranium atoms react with $\mathrm{O}_{2}$ in a stepwise fashion such as

$$
\begin{aligned}
\mathrm{U}+\mathrm{O}_{2} & \rightarrow \mathrm{UO}+\mathrm{O} \\
\mathrm{UO}+\mathrm{O}_{2} & \rightarrow \mathrm{UO}_{2}+\mathrm{O} \\
\mathrm{UO}_{2}+\mathrm{O}_{2} & \rightarrow \mathrm{UO}_{3}+\mathrm{O} \\
\mathrm{O}+\mathrm{O}_{2} & \rightarrow \mathrm{O}_{3}
\end{aligned}
$$

In our experiments to date, we cannot differentiate between the formation of $\mathrm{UO}_{2}^{+}$and $\mathrm{UO}_{2}$ or $\mathrm{UO}^{+}$and UO. The reactions of $\mathrm{U}+\mathrm{N}_{2} \mathrm{O}$ proceed in a similar stepwise fashion. The vibrational assignment for $\mathrm{UO}_{2}$ given by Gabelnick et al. [5, 6] and Carstens et al. [4] is the correct one. The appearance of two bands in the stretching region assignable to $\mathrm{UO}_{3}$ indicates that this species has $\mathrm{C}_{3 \mathrm{v}}$ or lower symmetry (only one vibrational mode of a planar $D_{3 \mathrm{~h}}$ species is infrared active). Attempts to fit the observed isotopic stretching frequencies of $\mathrm{U}^{16,{ }^{18}} \mathrm{O}_{3}$ to a $\mathrm{C}_{3 \mathrm{v}}$ model have not been successful. This suggests a lower symmetry (perhaps $\mathrm{C}_{2 \mathrm{v}}$ for the $\mathrm{UO}_{3}$ molecule). However a definitive choice of the geometry for this species will have to await a complete vibrational analysis of all the vibrational modes of $\mathrm{UO}_{3}$ and its isotopic variants.

\section{References and Note}

[1] Abramowitz, S., Acquista, N., and Thompson, K. R., J. Phys. Chem. 75, 2281 (1971).

[2] Abramowitz, S., and Acquista, N., J. Phys. Chem. 76, 648 (1972).

[3] Leary, H. J., Rooney, T. A., Cater, E. D., and Friedrick, H. B., High Temp. Sci. 3, 433 (1971).

[4] Carstens, D. H. W., Gruen, D. M., and Kozlowski, J. F., High Temp. Sci. 4, 436 (1972).

[5] Gabelnick, S. D., Reedy, G. T., and Chasanov, M. G., Chem. Phys. Letters 19, 90 (1973).

[6] Gabelnick, S. D., Reedy, G. T., and Chasanov, M. G., J. Chem. Phys. 58, 4468 (1973).

[7] Certain commercial apparatus are identified to specify adequately the experimental procedure. In no case does such identification imply recommendation or endorsement by NBS.

[8] Fite, W. L., and Irving, P., J. Chem. Phys. 56, 4227 (1972).

[9] Ackermann, R. J., Rauh, E. G., and Chandrasekharaiah, N. S., J. Phys. Chem. 73, 762 (1969).

(Paper 78A3-823) 


\title{
Publications of the National Bureau of Standards*
}

\author{
Citations with Selected Abstracts
}

J. Res. Nat. Bur. Stand. (U.S.), $78 \mathbf{A}$ (Phys. and Chem.), No. 2, (Mar.Apr. 1974), SD Catalog No. C13.22/sec.A:78/2.

The formation of curved polymer crystals: Polyoxymethylene, F. Khoury and J. D. Barnes.

Solid-phase behavior of several long-chain n-paraffins, esters, and a ketone, Peter K. Sullivan.

Simultaneous measurements of heat capacity, electrical resistivity, and hemispherical total emittance by a pulse heating technique: Vanadium, 1500 to $2100 \mathrm{~K}$, A. Cezairliyan, F. Righini, and J. L. McClure.

The shape of idealized grain boundaries, S. R. Coriell.

Reactions of fluorocarbon ions in $\mathrm{C}_{2} \mathrm{~F}_{6}$. Implications for the radiolysis, L. W. Sieck, R. Gorden, Jr., and P. Ausloos.

A simple technique for the generation of dilute mixtures of pollutant gases, W. Tsang.

Energy levels and classified lines in the second spectrum of thorium (Th II), R. Zalubas and C. H. Corliss.

Proposed secondary wavelength standards and line classifications in thorium spectra between 0.9 and $3 \mu \mathrm{m}, \mathrm{A}$. Giacchetti, J. Blaise, C. H. Corliss, and R. Zalubas.

Monogr. 25, Section 11. Standard x-ray diffraction powder patterns. Section 11 -data for 70 substances, H. E. Swanson, H. F. McMurdie, M. C. Morris, E. H. Evans, B. Paretzkin, J. H. de Groot, and S. J. Carmel, Nat. Bur. Stand. (U.S.), Monogr. 25-Sec. 11, 134 pages (Feb. 1974) SD Catalog No. C13.44:25/Sec. 11, \$1.55.

Key words: Crystal structure; integrated intensities; lattice constants; peak intensities, powder patterns; reference intensities; standard; x-ray diffraction.

Standard $\mathrm{x}$-ray diffraction patterns are presented for 70 substances. Fifty-two of these patterns represent experimental data and 18 are calculated. The experimental x-ray powder diffraction patterns were obtained with an x-ray diffractometer. All d-values were assigned Miller indices determined by comparison with computer interplanar spacings consistent with space group extinctions. The densities and lattice constants were calculated, and the refractive indices were measured whenever possible. The calculated $\mathrm{x}$-ray powder diffraction patterns were computed from published crystal structure data. Both peak height and integrated intensities are reported for the calculated patterns.

Monogr. 133. Mass and mass values, P. E. Pontius, Nat. Bur. Stand. (U.S.), Monogr. 133, 39 pages (Jan. 1974) SD Catalog No. C13. $44: 133,70$ cents.

*Publications with prices and SD Catalog numbers may be purchased directly from the Superintendent of Documents, U.S. Government Printing Office, Washington, D.C. 20402 (foreign: onefourth additional). Microfiche copies are available from the National Technical Information Service (NTIS), Springfield, Va. 22151. Reprints from outside journals and the NBS Journal of Research may often be obtained directly from the authors.
Key words: Apparent mass; buoyancy corrections; mass comparison; mass value; true mass; weighing.

There are several bases for assigning mass values to weights to be used as mass standards. As a consequence a given weight may have several assigned mass values depending on the basis used. In many cases, the differences between these assigned values, although easily detectable with precise weighing equipment, are of no practical concern. However, in some instances these differences may be crucial. The first part of this paper is a historical summary of weighing, standards, and the assignment of value; and the interfacing of mass measurements with civilization. The second part of this paper discusses in detail the methods of assigning mass values. Ways to convert from values on one basis to values on another basis are discussed. Sample problems relating to the buoyant effect of the air are presented in the appendices.

H113. CODASYL data description language. Journal of Development, June 1973, Nat. Bur. Stand. (U.S.), Handb. 113, 155 pages (Jan. 1974) SD Catalog No. C13.6/2:113, \$1.70.

Key words: COBOL; CODASYL; data base administration; data base management; data base task group; data description language.

This Journal of Development reports the work of the CODASYL Data Description Language Committee. The Committee was assigned the tasks of establishing "ways to aid the functions of data administration and systems administration." The Committee's charter included, "the provision of specifications for the declarations required to establish and maintain data base structures." As a step towards this purpose, the Journal contains three sections which treat the Background and History of the Data Description Language Committee, Major Concepts, and the specifications of the Data Description Language. The Committee based its work, in part, on the 1971 report of the Data Base Task Group Report.

The approved Data Description Language specifications contain the syntax and semantic rules that permit the description of the structure and contents of a data base in a language independent of, but common to, many other high level programming languages. The language specifications will have a significant impact on the development of functionally compatible data base management systems and will increase the portability of programs between different computer systems.

Though not part of the approved language specifications, the presentation of the major concepts will help in the understanding of the specifications. Similarly, the background and history information will help explain the evolutionary growth of the Data Description Language.

SP260-47. Standard reference materials: Electrical resistivity of electrolytic iron, SRM 797, and austenitic stainless steel, SRM 798, from 5 to 280 K, J. G. Hust, Nat. Bur. Stand. (U.S.), Spec. Publ. 260-47, 20 pages (Feb. 1974) SD Catalog No. C13.10:260-47, 55 cents.

Key words: Austenitic stainless steel; cryogenics; electrical re- 
sistivity; electrolytic iron; Lorenz ratio; standard reference material.

Electrical resistivity data are presented for characterized electrolytic iron, SRM 797, and austenitic stainless steel, SRM 798, at temperatures from 5 to $280 \mathrm{~K}$. Resistivities at ice and liquid helium temperatures were determined for 22 randomly selected iron specimens and the same number of steel specimens. These data indicate that the effect of material variability is about 1 percent for each of these SRM's.

SP366. Supplement 1. Bibliography on atomic line shapes and shifts (April 1972 through June 1973), J. R. Fuhr, L. J. Roszman, and W. L. Wiese, Nat. Bur. Stand. (U.S.), Spec. Publ. 366 Suppl. 1, 73 pages (Jan. 1974) SD Catalog No. C13.10:366, Suppl. $1, \$ 1.05$.

Key words: Atomic; instrumental broadening; line shapes; line shifts; pressure broadening; resonance broadening; Stark broadening; Van der Waals broadening.

This is the first supplement to the NBS Special Publication 366, "Bibliography on Atomic Line Shapes and Shifts (1889 through March 1972)." It contains about 350 references and covers the literature from April 1972 through June 1973. The bibliography contains five major parts: (1) All general interest papers are cataloged according to the broadening mechanisms (and, further, according to special topics under several of the mechanisms) and as to whether the work is a general theory, a general review, a table of profiles or parameters, a comment on existing work, a study of general experimental measurement techniques, or an experimental effort of general importance. Also included are selected papers on important applications of line broadening and on miscellaneous topics relating to atomic spectral line shapes and shifts. (2) In Part 2, all papers containing numerical data are ordered as to element, ionization stage, broadening mechanism (in the case of foreign gas broadening the perturbing species are listed), and it is indicated whether the data are experimentally or theoretically derived. (3) While in the two preceding parts of the bibliography the references are listed for brevity by identification numbers only, in Part 3 all references are listed completely by journal, authors, and title and are arranged chronologically and alphabetically within each year according to the principal author. (4) This section contains a list of all authors and their papers. (5) A final section provides corrections or additions to our first bibliography.

SP400-2. Semiconductor measurement technology: Microelectronic ultrasonic bonding, G. G. Harman, Ed., Nat. Bur. Stand. (U.S.), Spec. Publ. 400-2, 109 pages (Jan. 1974) SD Catalog No. C13.10:400-2, \$1.25.

Key words: Bonding; degradation (wire bond); discrete devices; electrical interconnection; fabrication (wire bond); failure (wire bond); hybrid circuits; integrated circuits; microelectronics; reliability; semiconductor devices; testing (wire bond); ultrasonic bonding; wire bond.

This report primarily comprises excerpts of the work done under the NBS ultrasonic wire bonding program that was previously published in 17 quarterly and other reports. The material is organized into subject groupings with the intention of presenting in convenient form sufficient information for making high quality ultrasonic wire bonds as well as imparting a basic understanding of the ultrasonic systems used. The work emphasizes problems and methods of solving them. To accomplish this, the required measurement equipment is first introduced. This is followed by procedures and techniques used in setting up a bonding machine, and then various machine- or operator-induced reliability problems are discussed. The characterization of the ultrasonic system and its problems are followed by in-process bonding studies and work on the ultrasonic bonding (welding) mechanism. The report concludes with a discussion of various effects of bond geometry and wire metallurgical characteristics. Where appropriate, the latest, most accurate value of a particular measurement has been substituted for an earlier reported one. Thus all of the included material is up to date.

SP400-3. Semiconductor measurement technology: ARPA/NBS workshop I. Measurement problems in integrated circuit processing and assembly, $H$. A. Schafft, Nat. Bur. Stand. (U.S.), Spec. Publ. 400-3, 24 pages (Feb. 1974) SD Catalog No. C13.10:400-3, 60 cents.

Key words: Die bonding; hermeticity; integrated circuits; measurement methods; microelectronics; oxides; photolithography; process control; reliability; semiconductor devices; silicon; wire bonding.

The dual purpose of the workshop was (1) to announce and describe the new effort, "Advancement of Reliability, Processing, and Automation for Integrated Circuits with the National Bureau of Standards," sponsored by the Defense Advanced Research Projects Agency (ARPA), and (2) to obtain additional input on critical measurement problems in integrated circuit processing and assembly to assist in planning future work in the effort. More than 130 engineers representing 61 organizations from the electronics industry and government participated in the workshop. The measurement problems in silicon, oxides, photolithography, and assembly and the problems in information dissemination that were identified by the participants are summarized. Included as appendices are summaries of two talks given: one which described the results of earlier direct contacts with a cross section of industrial representatives on major measurement problems in integrated circuit processing and assembly and the other which described the initial plans for work in the new effort.

BSS48. Design, siting, and construction of low-cost housing and community buildings to better withstand earthquakes and windstorms, W. F. Reps and E. Simiu, Eds., Nat. Bur. Stand. (U.S.), Bldg. Sci. Ser. 48, 152 pages (Jan. 1974) SD Catalog No. C13.29/2:48, $\$ 4.85$.

Key words: Buildings; construction; design; developing countries; earthquakes; low-cost housing; natural disasters; structures; windstorms.

The extensive loss of life and property caused in developing countries by earthquakes and windstorms (hurric anes, typhoons and tropical cyclones) may be reduced to a considerable degree by the adoption and implementation of improved design, siting and construction procedures practicable within the context of the cultural and socioeconomic constraints prevailing in these countries.

The report provides technical information regarding characteristics of materials and building systems, and discusses the structural performance of buildings subjected to the action of earthquakes and wind forces with specific reference to structures typical of developing countries. Potential ways are described in which structures can be made more resistant to such action. Siting considerations are discussed from a geological, seismic and climatological viewpoint, and recommendations relating to siting problems are made. Techniques of housing construction, both traditional and industrialized, are described and improvements resulting in better earthquake or windstorm resistance are suggested. Building codes, their improvement and their enforcement are also discussed.

The report discusses cultural and socio-economic constraints influencing the adoption of improved practices, describes various feasible technical improvements of construction materials, composite systems and building systems, identifies mechanisms for stimulating technical improvements and discusses the role of institutions in this regard. Throughout the report, specific references are made to Peru, the Philippines and Turkey, countries which suffer from frequent devastation from natural disasters such as earthquakes and typhoons and which were selected as case studies for the purpose of this report. 
TN648. Thermophysical properties of nitrogen from the fusion line to $3500 \mathrm{R}(1944 \mathrm{~K})$ for pressures to $150,000 \mathrm{psia}$ $\left(10342 \times 10^{5} \mathbf{N} / \mathbf{m}^{2}\right)$, R. T. Jacobsen, R. B. Stewart, R. D. McCarty, and H. J. M. Hanley, Nat. Bur. Stand. (U.S.), Tech. Note 648, 162 pages (Dec. 1973) SD Catalog No. C13.46:648, \$1.25.

Key words: Density; dielectric constant; enthalpy; entropy; equation of state; fixed points; heat transfer coefficients; index of refraction; Joule-Thomson; latent heat; melting point; nitrogen; Prandtl number; specific heat; speed of sound; surface tension; thermal conductivity; thermal diffusivity; vapor pressure; viscosity; volume.

Tables of thermophysical properties of nitrogen are presented for temperatures from the fusion line to $3500 \mathrm{R}$ for pressures to 3000 psia, and from the fusion line to $1500 \mathrm{R}$ for pressures above $3000 \mathrm{psia}$ to $150,000 \mathrm{psia}$. The tables include values of entropy, enthalpy, internal energy, density, specific volume, velocity of sound, specific heats $\left(\mathrm{C}_{v}\right.$ and $\left.\mathrm{C}_{p}\right)$, thermal conductivity, viscosity, thermal diffusivity, Prandtl number, and the dielectric constant for selected isobars. Additional tables are included for values of: $(\partial \mathrm{P} / \partial \mathrm{V})_{T},(\partial \mathrm{P} / \partial \mathrm{T})_{\rho}$, $\mathrm{V}(\partial \mathrm{H} / \partial \mathrm{V})_{\rho},(\partial \mathrm{P} / \partial \mathrm{U})_{v}, \mathrm{~V}(\partial \mathrm{P} / \partial \mathrm{V})_{T}$, and $(\partial \mathrm{V} / \partial \mathrm{T})_{p}$, which have special utility in heat transfer calculations. Tables of selected isobars for the liquid and vapor phases, and for the saturated vapor and saturated liquid are included.

An equation of state is presented for liquid and gaseous nitrogen for the temperature and pressure ranges of these tables. In the determination of the equation of state, all of the P- $\rho$-T (pressure-densitytemperature) data available from the published literature were reviewed, and appropriate corrections made to bring experimental temperatures into accord with the International Practical Temperature Scale of 1968. The coefficients of the equation of state were determined by a weighted least squares fit to selected P- $\rho$-T data and simultaneously to $\mathrm{C}_{v}$ data determined by corresponding states analysis from oxygen data, and to data which defined the phase equilibrium criteria for the saturated liquid and saturated vapor. A vapor pressure equation, melting curve equation, and an equation to represent the ideal gas heat capacity of nitrogen are also presented. The equation of state is estimated to be accurate to within 0.5 percent in the liquid region, to within 0.1 percent for supercritical isotherms up to 15,000 psia, and to within 0.3 percent from 15,000 to 150,000 psia. The vapor pressure equation is accurate to within $\pm 0.01 \mathrm{~K}$ between the triple point and the critical point.

TN800. Computer networking: Approaches to quality service assurance, R. B. Stillman, Nat. Bur. Stand. (U.S.), Tech. Note 800, 26 pages (Jan. 1974) SD Catalog No. C13.46:800, 60 cents.

Key words: Compiler; computer network; documentation; dynamic software analysis; interpreter; quality control; software testing; software verification; static software analysis; structured programming; system errors; system performance; theorem-proving.

The problem of quality service assurance in a (generalized) computer networking environment is addressed. In the absence of any direct, well-defined, quantitative measure of service quality and reliability, error collection and analysis is the only basis for service quality control. Therefore, mechanisms are described which facilitate reporting of operational errors, documentation of error corrections, and collection of system performance data. Since techniques for hardware quality control are well known, these mechanisms focus on collecting data which can be used to assess and control software quality. Finally, specific network facilities are described which support research in the area of software quality, and potential areas of new research using the network are identified.

TN804. Review of computer networking technology, R. P. Blanc, Nat. Bur. Stand. (U.S.), Tech. Note 804, 135 pages (Jan. 1974) SD Catalog No. C13.46:804, \$1.55.
Key words: Computer networks; computer-tc-computer transfers; interactive terminals; minicomputer-based systems; network configuration; remote job entry; resource sharing.

This report gives a descriptive summary of the technical characteristics of existing computer networks, including data communication technology and configuration related to support of resource sharing services for a computer network. Included are discussions of terminal support capabilities for the communications network and a development of relevant network terminology. The report concludes with a comparative evaluation of existing technological approaches to networking.

TN805. Network management survey, I. W. Cotton, Nat. Bur. Stand. (U.S.), Tech. Note 805, 91 pages (Feb. 1974) SD Catalog No. C13.46:805, \$1.20.

Key words: Computer network; management; network, network management.

This report presents the results of a study of management practices in different computer networks. Five networks were chosen as typical of different approaches to network implementation and management: Defense Advanced Research Projects Agency (ARPA) Network, MERIT Network, Triangle Universities Computation Center (TUCC), Oregon State Regional Network and Tymnet, a commercial network. A common format is employed to survey each network. While the report is not intended to be prescriptive, some empirical observations are presented for each topic covered.

TN809. Government looks at privacy and security in computer systems. A summary of a conference held at the $\mathrm{Na}$ tional Bureau of Standards, Gaithersburg, Maryland, November 19-20, 1973, C. R. Renninger and D. K. Branstad, Eds., Nat. Bur. Stand. (U.S.), Tech. Note 809, 47 pages (Feb. 1974) SD Catalog No. C13.46:809, 85 cents.

Key words: Computer systems, privacy and security; confidentiality; privacy; security.

This publication summarizes the proceedings of a conference held for the purpose of highlighting the needs and problems of Federal, State and local government in safeguarding individual privacy and protecting confidential data contained in computer systems from loss or misuse. The Conference was held at the National Bureau of Standards on November 19-20, 1973.

The origin of governmental problems is discussed in the context of the public's concern for privacy arising out of computer-based recordkeeping, the diverse legislative actions now being taken to safeguard privacy, the threats to the security of computer-based information systems and the technological problems associated with protecting against such threats. Useful distinctions are drawn between privacy, confidentiality and security to clarify the issues and allocate responsibilities for solving the problem among lawmakers, technologists and management.

Major needs are described. These include the need for cohesive Federal, State and local legislation, technological guidelines and standards for assuring uniform compliance with legislative requirements; management guidelines for identifying and evaluating threats to security; and improved technological mechanisms for controlling access to computer systems and networks. Cost implications of providing security measures are discussed.

TN813. NBS Reactor: Summary of activities July 1972 to June 1973, R. S. Carter, Nat. Bur. Stand. (U.S.), Tech. Note 813, 135 pages (Feb. 1974) SD Catalog No. C13.46:813, \$1.55.

Key words: Activation analysis; crystal structure; diffraction; isotopes; molecular dynamics; neutron; nuclear reactor; radiation. 
This report summarizes all those programs which depend on the NBS reactor. It covers the period from July 1972 through June 1973. The programs range from the use of neutron beams to study the structure and dynamics of materials through nuclear physics and neutron standards to sample irradiations for activation analysis, isotope production and radiation effects studies.

TN814. A mechanized information services catalog, B. Marron, E. Fong, and D. Fife, Nat. Bur. Stand. (U.S.), Tech. Note 814, 56 pages (Feb. 1974) SD Catalog No. C13.46:814, 90 cents.

Key words: Bibliographic data bases; computer-based systems; information services; information systems.

NBS is mechanizing a catalog of currently available information sources and services. Information from recent surveys of machinereadable, commercially-available bibliographic data bases, and the various current awareness, batch retrospective, and interactive retrospective services which can access them, has been correlated and converted into a machine-readable data base. A prototype searching capability has been established on an operational interactive retrieval system. Reasons for establishing the catalog and the choice of the initial information are detailed and the prototype implementation is described. Sample queries are included, as well as a todate listing of the catalog. Plans for future development are discussed.

TN815. Fire accidents involving the ignition of sleepwear worn by children under the age of three, $\mathrm{E}$. A. Tyrrell, Nat. Bur. Stand. (U.S.), Tech. Note 815, 23 pages (Feb. 1974) SD Catalog No. C13.46:815, 60 cents.

Key words: Accidents; burn injuries; case histories; children's sleepwear; fabric fires; FFACTS; fires; flammable fabrics; garment fires; ignition sources; standards.

Accident case histories of children under age 3 involved in sleep wear fires are examined in detail. Of 434 persons involved in sleepwear ignition incidents in the NBS Flammable Fabrics Accident Case and Testing System as of January 1973, 101 were children under age $6 ; 22$ of these were children under age 3 . In 15 of these 22 accidents, the child was a victim of his own actions, while in 7 more accidents, the child played a passive role in the ignition sequence. Matches and kitchen ranges were the most frequent ignition sources found for this group of children. Seven of these small children died; the remaining 15 victims sustained burn injuries covering from one to 65 percent of their bodies. Most of the sleepwear items involved in these 22 accidents were made of cotton and 14 of these 22 items were pajamas. Children under age 3 were most frequently involved in fire accidents during the morning hours in the kitchen or bedroom. Only one child was under the supervision of an adult at the time of the accident. From the information found in the case history reports, an analysis of the severity of the injuries received by the victims was made and it was determined that the severity of the injuries received by one of the 3 infants under the age of one and 15 of the remaining 19 one- and two-year-olds probably would have been reduced if they had been afforded the protection of a flammability standard.

TN816. Engineering and construction manual for an instrument to make burn hazard measurements in consumer products, L. A. Marzetta, Nat. Bur. Stand. (U.S.), Tech. Note 816, 48 pages (Feb. 1974) SD Catalog No. C13.46:816, 85 cents.

Key words: Consumer products; contact temperature; thermesthesiometer; thermometry.

Surface temperature measurement alone is insufficient to establish the hazard of human contact with a hot or cold object. A metal surface is more likely to cause thermal injury than a plastic surface at the same temperature. An instrument equipped with a measuring probe has been developed for indicating the tissue temperature that would be experienced if human contact were made with the hot surface in question. The correct value of interface contact temperature can be read for a selected contact time without knowing the composition or temperature of the heated material under test.

A detailed set of instructions and drawings for assisting in the construction of the device is included in the manual. Several test procedures are described for use in checking the performance of the measuring probe and instrument.

TN818. Occupant behavior in building fires, A. I. Rubin and A. Cohen, Nat. Bur. Stand. (U.S.), Tech. Note 818, 28 pages (Feb. 1974) SD Catalog No. C13.46:818, 60 cents.

Key words: Disaster research; high rise building fires; occupant safety.

Fire safety in buildings is important in building design and the formulation of codes and standards. However, an examination of the information concerning the needs of occupants in fire emergencies (as opposed to ensuring a degree of structural integrity for the building) indicates that the scientific information base is woefully inadequate. The increasing prominence of high rise buildings having many occupants intensifies the need for better information about the behavior of occupants during fire emergencies. Fire researchers have indicated that it is often not feasible to evacuate buildings because of time constraints. Instead, designers use techniques such as safe areas within buildings and requiring people to respond differentially, based on their particular location. This approach emphasizes communications and warning systems to transmit messages. These systems such as loud noises or blinking lights should be designed to "take advantage" of the usual responses made by people. Occupants can actively be a part of the fire warning and fighting system instead of being unwilling victims. This possibility is pursued and a human factors approach is taken to suggest some means of better understanding the capabilities of occupants.

NBSIR 73-202. Conservation via effective use of energy at the point of consumption, C. A. Berg, 37 pages (Apr. 1973). Order from NTIS as COM 74-10479.

Key words: Buildings; energy conservation; industrial equipment.

The practices and equipment employed at the point of energy consumption in buildings and in industrial processes permit excessive consumption of energy. It is estimated that if full application of the economically justifiable technical improvements presently available were made to equipment and practices in buildings and industry, as much as 25 percent of the total primary fuel consumption in the U.S.A. could be conserved. The reasons why economically justifiable application of effective technology at the point of energy consumption has not been widely adopted in the past are considered. The needs to facilitate adoption of effective equipment and practices in the future are discussed.

NBSIR 73-287. Procedures for the calibration of volumetric test measures, J. F. Houser, 24 pages (Aug. 1973). Order from NTIS as COM 73-11928/1GA.

Key words: Air density; calibration; gravimetric; neck; volumetric;

The values for graduated neck type volumetric vessels may be obtained by either gravimetric or volumetric calibrations. This text describes the two methods of calibration and the data reduction associated with each method. Procedures for preparing these vessels for test are discussed. Also included are illustrations for data recording.

NBSIR 73-304. Reference-waveform generation using Debye dielectric dispersion, N. S. Nahman, R. M. Jickling, and D. R. Holt, 98 pages (Dec. 1972). Order from NTIS as COM 74-10281.

Key words: Pulse distortion in transmission lines; pulse techniques; reference waveform generation; time domain mea- 
surements; transient response Debye dielectric.

This report discusses the theory, construction, and operation of Reference-Waveform Generators using a tunnel diode transitionwaveform generator driving 4.65 meter (15 foot), 3.10 meter (10 foot), and 1.55 meter ( 5 foot) liquid-dielectric uniform lossy coaxial lines to produce known 0.2 volt transition waveforms across $50 \mathrm{ohms}$ with $(10-90 \%)$ transition times from 205 to 560 picosecond. Each resultant Available-Waveform is characterized in terms of its departure from the step response of the uniform lossy coaxial line operating into a 50 ohm load. The liquid dielectric solutions are dispersive with relaxation times of the order of 4 picoseconds in which heptane is the solvent and the ketones, butanone, heptanone and octanone are the solutes in concentrations ranging from 0.25 - to 2-molal.

NBSIR 73-316. Liquid helium pumps, P. M. McConnell, 90 pages (June 1973). Order from NTIS as AD 769542.

Key words: Cavitation; helium; pump performance; pumps; superfluid.

This report summarizes studies of pump characteristics and performance in supercritical, normally boiling, and superfluid helium, and also presents results on a survey of commercially available pumps for helium service. Experimental measurements were made on a centrifugal pump which produced a maximum head of about 15 meters and a maximum flow of about $2.5 \times 10^{-4} \mathrm{~m}^{3} / \mathrm{s}$. Performance agreed approximately with classical affinity laws, but cavitation appeared to provide less of a performance limitation than expected. The survey turned up several pumps which have been used in helium, though relevant performance data is lacking.

NBSIR 73-331. Refrigeration of superconducting rotating machinery, V. D. Arp, 75 pages (June 1973). Order from NTIS as COM 74-10238.

Key words: Equation of state; helium; hydrodynamics; nearcritical flow; refrigeration; superconductors; thermodynamics.

Recent work at the NBS Cryogenics Division in three areas related to helium refrigeration is summarized: (1) Analysis is given of a possible high pressure refrigeration cycle which offers in principle a reduced component size, but which turns out to be impractical because of expansion engine inefficiencies. (2) Exact equations for flow of a real fluid are derived and applied to problems of fluid flow near the critical point, as may occur with some helium-cooled superconducting systems, and (3) Three new equations of state for helium are given, each using different state variables, to eliminate the need for iterative techniques in helium refrigeration cycle and fluid flow analysis.

NBSIR 73-339. Preliminary hydrogen freezing studies, D. E. Daney, W. G. Steward, and R. O. Voth, 281 pages (Oct. 1973). Order from NTIS as COM 73-11985/1GA.

Key words: Freezing rates; solid hydrogen; thawing; thermal conductivity.

The study summarized in this report is aimed at developing the technology required to fill space vehicle propellant tanks with solid hydrogen by in-place freezing. Planned continuation of this work was terminated with the loss of NERVA funding by the NASA. Therefore, progress to-date is summarized but substantial experimental results have not yet been obtained.

The program was to have been carried out in two phases: a mathematical analysis and experimental verification of the analysis. Freezing times and heat flux have been calculated for four geometrical shapes, and a range of sizes, refrigerant temperatures, ortho-para concentrations, and heat transfer coefficients. The results of these calculations are presented in generalized graphical form, in a total of 240 graphs.

The freezing experimental apparatus has been built and a preliminary test performed which generally demonstrates the validity of the analytical and experimental approaches. With only minor modifications the apparatus is ready for a full test program of hydrogen freezing and melting techniques.

NBSIR 73-345. Combustion of metals in oxygen phase II: Bulk burning experiments, A. H. Tench, H. M. Roder, and A. F. Clark, 49 pages (Dec. 1973). Order from NTIS as COM 74-10239.

Key words: Alloys; aluminum; combustion; ignition; oxygen; safety; stainless steel; steel, titanium.

This program was started to study combustion of the ordinary metals in oxygen, to provide information useful to designers of bulk oxygen handling equipment, particularly from the point of view of safety. We have studied the ignitability and combustability of carbon steels, stainless steels, aluminum alloys, titanium and copper metals, in oxygen atmospheres up to $60 \mathrm{psig}$. We encountered a violent reaction involving burning stainless steel and aluminum, a thermite reaction apparently, and have investigated this from a quantitative point of view. We have tried throughout to study the quantitative aspects of the combustion processes, and related quenching effects. Ordinary steel and stainless steel burn quite readily at these low oxygen pressures, and the stainless steel-aluminum reaction produces intense heat, with severe damage to neighboring structures. We are at the stage where further investigations could be carried out quite expeditiously and on a sound statistical basis.

NBSIR 73-346. RF total mass gauging in large storage containers: Empty tank modes, R. S. Collier and D. Ellerbruch, 28 pages (Oct. 1973). Order from NTIS as COM 74-10240.

Key words: LOX storage container; radio frequency; total mass gauging.

This report describes experiments to determine the feasibility of radio frequency (RF) mass gauging for fluids stored in large containers. The experiments were done at the NASA Mississippi Test Facility using the 460,000 gallon LOX Storage Tank as an electromagnetic resonant cavity. The results show that the RF gauging technique is feasible for large containers.

NBSIR 73-348. An engineering feasibility study for one-way time transfer using the GOES satellite ranging system, J. B. Milton and W. F. Hamilton, 38 pages (Dec. 1973). Order from NTIS as COM 74-10241.

Key words: Clock synchronization; one-way time transfer; satellite timing; synchronous satellite.

The Time and Frequency Division of the National Bureau of Standards has conducted an engineering study to determine the feasibility of using the GOES satellite ranging system for precise (0.1 microsecond, one-sigma) time transfer to a receiving-only timing site. The GOES satellite ranging system, termed a trilateration system, will accurately locate this satellite within some coordinate structure. The sources of time transfer errors have been studied in some detail. These errors can be caused by satellite location errors, ground station location errors, unknown delays caused by the troposphere, the ionosphere, and the various equipments. Simplified designs for an automatic and a manually operated timing site are presented. Some technical problems found in the associated equipment are discussed. The study indicates that a secondary, or slave site, clock could be synchronized to within 0.1 microsecond, one-sigma, of some master clock utilizing a one-way, or receiving-only system.

NBSIR 73-402. NBS materials science and manufacturing in space research, E. Passaglia and R. L. Parker, 127 pages (Nov. 1973). Order from NTIS as COM 74-10472.

Key words: Materials processing; perfection; purity; space manufacturing; space processing; zero-g.

This report describes NBS work for NASA in support of NASA's Materials Science and Manufacturing in Space (MS/MS) (now Space 
Processing) program, covering the period November 1, 1972 to October 31, 1973. The objectives of the NBS program are to perform ground-based studies of those aspects of space that could possibly provide a unique environment for making materials more perfect or more pure. The approach taken deals primarily with experimental and theoretical studies of the possible effects of the absence of gravitational forces on those materials preparation processes where the presence of gravity may be important in reducing perfection or purity. The materials preparation processes studied comprise 5 tasks in the areas of crystal growth, purification and chemical processing, and the preparation of composites.

\section{NBSIR 73-403. Development and analysis of techniques for} calibration of Kerr cell pulse-voltage measuring systems VII, E. C. Cassidy, R. E. Hebner, R. J. Sojka, and M. Zahn, 129 pages (Nov. 1, 1973). Order from NTIS as COM 74-10016/5GA.

Key words: Electric field measurement; electro-optic Kerr effect; high voltage measurement; impulse measurement; Kerr constant; liquid insulants; nitrobenzene; peak reading voltmeter; space charge.

To improve the accuracy of pulse voltage systems using the electro-optic Kerr effect, it is necessary to improve the accuracy of calibration of Kerr cells. In the past this has been attempted by calibrating the cell under direct voltage and relying on the frequency independence of the Kerr coefficient (below $10^{8} \mathrm{~Hz}$ ) to insure that the calibration was valid under high voltage pulses. Space charge effects, however, modify the electric field distribution in the liquid under direct high voltage. The electric field and space charge behavior in nitrobenzene have therefore been documented as functions of the level and frequency of the applied voltage. In addition, to improve the efficiency of cell design and to facilitate the investigation of other liquids for use in Kerr cells, the electro-optic Kerr coefficient of nitrobenzene has been measured as a function of temperature and wavelength. Finally a new peak reading voltmeter based on the Kerr effect is described and the results of using the electro-optic Kerr effect to measure the voltage pulses in medical $x$-ray machines are presented.

NBSIR 73-417. Evaluation of commercial integrating-type noise exposure meters, W. A. Leasure, Jr., R. L. Fisher, and M. A. Cadoff, 33 pages (Dec. 1973). Order from NTIS as COM 7410477.

Key words: Acoustics (sound); dosimeter; environmental acoustics; instrumentation; noise exposure; noise exposure meters.

As a result of the promulgation of occupational noise exposure regulations by the Federal government, there are a number of commercial noise exposure meters on the market today that provide a measure of noise integrated (with appropriate weighting) over a time interval. This report presents the results of an evaluation of such instruments by the National Bureau of Standards (under the sponsorship of the U.S. Environmental Protection Agency) as to their usefulness in monitoring compliance with occupational noise regulations as well as their applicability as instruments for use in achieving the broader goals of the EPA. Tests were designed and conducted to evaluate microphone and system response to sound of random incidence, frequency response, crest factor capability, accuracy of the exchange rate circuitry, performance of the noise exposure meter as a function of temperature, and the dependence of the device on battery voltage. The rationale of the test procedures utilized to evaluate overall system as well as specific performance attributes, details of the measurement techniques, and results obtained are discussed.

NBSIR 74-442. High temperature slow crack growth in ceramic materials, A. G. Evans, 48 pages (Feb. 1974). Order from NTIS as COM 74-10476.

Key words: Ceramics; crack healing; crack propagation; cyclic fatigue; failure prediction; high temperature; static fatigue.
High temperature slow crack growth processes in several ceramic materials are examined under static and cyclic loading conditions. Data obtained at temperatures up to $1400{ }^{\circ} \mathrm{C}$ are used for purposes of failure prediction and for analysis of the slow crack growth phenomena. It is shown that purity plays a major role in slow crack growth resistance, particularly in the hot pressed materials, and that cycling in the low frequency regime does not significantly increase the rate of slow crack growth. The slow crack growth mechanisms appear to be primarily plasticity related. Two semi-quantitative mechanisms are presented, one due to dislocation motion and the other due to grain boundary sliding.

This column lists all outside publications by the NBS staff, as soon after issuance as practical. For completeness, earlier references not previously reported may be included from time to time.

Arni, H. T., Precision of air-permeability, turbidimeter, and No. 325 sieve fineness data, Amer. Soc. Testing Mater. Spec. Tech. Publ. 473, pp. 20-44 (1970).

Key words: Air-permeability; cements; fineness; No. 325 sieve; portland cements; precision; tests; Wagner turbidimeter.

Data on air-permeability and turbidimeter fineness from an interlaboratory test program involving eight different portland cements and from about 80 to 150 laboratories over a period of a year and a half are presented and analyzed from the standpoint of betweenlaboratory and within-laboratory precision. Scatter diagrams for the four pairs of samples are presented and used as an aid in the analysis. For six of the cements, results of determinations of fineness by the No. 325 sieve are also analyzed and scatter diagrams shown. The effect on the calculated standard deviation of the elimination of some outlying results is assessed. A method of determining within-laboratory or single-laboratory precision without the use of duplicate determinations is presented. Laboratory bias was found to be significantly larger than the random error for all three tests. There was no indication of any significant difference in precision or in laboratory bias between the Type I and Type IA cements for any of the tests.

Bagus, P. S., Krauss, M., LaVilla, R. E., The threshold region of the methane carbon K-absorption spectrum, Chem. Phys. Lett. 23, No. 1, 13-17 (Nov. 1, 1973).

Key words: Carbon-K-absorption threshold; first Rydberg transition; $\mathrm{la}_{1}{ }^{-1}$ hole state calculation; methane; vibronic transition.

The carbon K-absorption of $\mathrm{CH}_{4}$ is analyzed with the help of an ab initio calculation of the Rydberg states of $\mathrm{la}_{1}{ }^{-1}$ hole state. The strong absorption peak at $288.3 \mathrm{eV}$ is identified as the first Rydberg $2 \mathrm{t}^{*} \leftarrow$ $\mathrm{la}_{1}$, whose calculated ionization potential is in good agreement with experiment. Also, the oscillator strength for this transition was calculated to be $f=1.9 \times 10^{-2}$, which is within the estimated margin of error of the experimental $f=0.6 \times 10^{-2}$. The weak peak at $287.2 \mathrm{eV}$ is interpreted as a vibronic transition to the $3 a_{1}(3 \mathrm{~s})$ Rydberg. An estimate of its oscillator strength as 10 percent of the allowed $2 t(3 p)$ Rydberg line is consistent with experiment. For the case of $\mathrm{CD}_{4}$, this weak forbidden transition was estimated to be 20 percent of the allowed $2 \mathrm{t}(3 \mathrm{p})$ Rydberg line.

Ballard, D. B., A resolution test sample for the scanning electron microscope, (Proc. 30th Annual Meeting on Electron Microscopy Society of America, Los Angeles, Calif., Aug. 14-18, 1972), Paper in 8th Annual Proceedings Electron Microscopy Society of America, C. J. Arceneaux, Ed., pp. 446-447 (Claitor's Publishing Division, Baton Rouge, La., Aug. 1972).

Key words: Al-W alloy; resolution test specimen; SEM; specimen criteria.

A test sample that satisfies the restrictive specimen criteria discussed previously [1] for a resolution determination of the SEM is essential. At present, the use of a resolution sample made from a specimen well-known to the particular operator who carries out measurements on the subsequent photomicrograph is the usual 
procedure. The aluminum-tungsten (Al-W) dendritic structure (located at arrow) in figure 1 that remains on the crystal surface of the bead resulting from the melting of aluminum on a hot tungsten filament, provides such a specimen.

Bass, A. M., Laufer, A. H., The methyl radical combination rate constant as determined by kinetic spectroscopy, Int. J. Chem. Kinet. V, 1053-1065 (1973).

Key words: Absorption spectroscopy; combination; f-number; methyl; radical; rate constant.

The rate constant for the reaction

$$
\mathrm{CH}_{3}+\mathrm{CH}_{3}+\mathrm{M} \stackrel{k_{1}}{\rightarrow} \mathrm{C}_{2} \mathrm{H}_{6}+\mathrm{M} \quad(\mathrm{M}=\mathrm{He})
$$

has been determined by means of vacuum ultraviolet flash photolysis and time-resolved kinetic spectroscopic observations of the 1504- $\AA$ absorption band of $\mathrm{CH}_{3}$. The measurements made using three different sources of methyl radicals (azomethane, dimethylmercury, and ketene-hydrogen) were in accord and yielded a value for the rate constant of $k_{1}=(9.53 \pm 1.17) \times 10^{-11} \mathrm{cc} \mathrm{molec}^{-1} \mathrm{sec}^{-1}$. A detailed error analysis is presented. The $f$-value for the 1504 - $\AA$ band of $\mathrm{CH}_{3}$ is determined to be $(2.5 \pm 0.7) \times 10^{-2}$.

Bender, P. L., Currie, D. G., Dicke, R. H., Eckhardt, D. H., Faller, J. E., Kaula, W. M., Mulholland, J. D., Plotkin, H. H., Poultney, S. K., Silverberg, E. C., Wilkinson, D. T., Williams, J. G., Alley, C. O., The lunar laser ranging experiment, Science 182, 229-238 (Oct. 1973).

Key words: Celestial mechanics; crustal movements; earth rotation; geophysics; laser; moon; polar motion; selenodosy.

The data obtained so far by the McDonald Observatory have been used to generate a new lunar ephemeris based on direct numerical integration of the equations of motion for the moon and planets. With this ephemeris, the range to the three Apollo retroreflectors can be fit to an accuracy of 5 meters by adjusting the differences in momenta of inertia of the moon about its principal axes, the selenocentric coordinates of the reflectors, and the McDonald longitude. The accuracy of fitting the results is limited currently by errors of a few arc sec in the angular orientation of the moon, as derived from the best available theory of how the moon rotates in response to the torques acting on it. A new calculation of the moon's orientation as a function of time based on direct numerical integration of the torque equations is expected to considerably improve the accuracy of fitting the data.

Bennett, L. H., Swartzendruber, L. J., McNeil, M. B., On the electron-configuration theory of marine corrosion, (Proc. $3 \mathrm{~d}$ Int. Congress on Marine Corrosion and Fouling, Gaithersburg, Md., Oct. 2-6, 1972), Paper in Proceedings: Third International Congress on Marine Corrosion and Fouling, pp. 410-426 (Northwestern University Press, Evanston, Ill., Oct. 1973).

Key words: Alloy theory; catalysis; chemisorption; $\mathrm{Cu}-\mathrm{Ni}$ alloys; d-bands; electron-configuration; metallurgy; passivity; rigidband model; saltwater corrosion; surfaces.

The electron-configuration theory of corrosion introduced by Uhlig relates chemisorption and passivity to alloy compositions having favorable d-electron configurations. This theory postulates a critical composition for passivity which coincides with a theoretical filling of the d-band in a "rigid-band" description of these alloys. Recently, detailed knowledge of the electronic structure of $\mathrm{Cu}-\mathrm{Ni}$ alloys has been greatly increased, and it no longer appears that a strict band model alone can give an adequate description of the disordered alloys. Recent theories and modern spectroscopic methods, including soft $x$-ray and photoelectron spectroscopy and other techniques, have provided a great deal of new knowledge concerning the electronic structure of $\mathrm{Cu}-\mathrm{Ni}$ alloys. In light of these experimental and theoretical developments, this paper investigates whether or not there is any evidence to support an electron-configuration theory of corrosion, without regard to the question of passivity, for $\mathrm{Cu}-\mathrm{Ni}$ alloys in salt- water. The addition of small amounts of Fe has important effects on the corrosion rate in the copper-rich alloys and the relevance of this to the electron-configuration theory is considered. Effects of metallurgical variables and of film properties are noted. The related topic of heterogeneous catalysis is discussed.

Berger, M. J., Beta-ray dose in tissue-equivalent material immersed in a radioactive cloud, Health Phys. 26, 1-12 (Jan. 1974).

Key words: Beta-rays; depth-dose; dosimetry; electrons; immersion problem; radioactive cloud.

The radioactive-cloud immersion problem for beta-radiation has been treated schematically by assuming a semi-infinite air medium (source region) located adjacent to a semi-infinite water medium (tissue-equivalent target). The source region has been assumed to contain a uniform concentration of beta-emitting radionuclide, and calculations have been made of the absorbed-dose distribution (depth dose) in the water target. A leakage correction has also been made to estimate the reduction of absorbed dose that would occur if the target had lateral dimensions small compared to the beta-particle range in air. Depth-dose calculations have been carried out for various source spectra (including beta-ray as well as discrete electron spectra) for 15 radionuclides (rare gases) emitted by nuclear power plants into the atmosphere, and for 12 other commonly used radionulides.

Billingsley, F. P. II, Calculation of the absolute infrared intensities for the $0-1,0-2$ and $1-2$ vibration-rotation transitions in the ground state of $\mathrm{NO}^{+}$, Chem. Phys. Lett. 23, No. 2, 160166 (Nov. 15, 1973).

Key words: Dipole moment function; infrared intensities; multiconfiguration; $\mathrm{NO}^{+}$.

The absolute infrared intensities of the $0-1,0-2$ and $1-2$ vibrationrotation bands in the ${ }^{1} \Sigma+$ ground state have been calculated from first principles. The dipole moment function for $\mathrm{NO}^{+}$was determined in the region of the equilibrium internuclear separation by an accurate multi-configuration self-consistent-field procedure. The dipole matrix elements over vibration states were solved exactly using numerical techniques. The ratio of the calculated integrated absorption coefficients for the fundamental and first overtone $\left(88.8 \mathrm{~cm}^{-2} \mathrm{~atm}^{-1}\right.$ and 0.6 $\mathrm{cm}^{-2} \mathrm{~atm}^{-1}$, respectively, at $273.16 \mathrm{~K}$ ) is in reasonable agreement with an estimate based on observation of these bands in $\mathrm{NO}^{+}$at high altitudes in the upper atmosphere.

Blevin, W. R., Sinusoidal radiation chopper, Appl. Opt. 12, No. 12, 2802 (Dec. 1973).

Key words: Radiation chopper; sinusoidal modulation.

A description is given of a simple method for modulating a beam of optical radiation sinusoidally.

Bur, A. J., Fetters, L. J., Intrinsic viscosity measurements on rodlike poly( $n$-butyl isocyanate) and poly(n-octyl isocyanate), Macromolecules 6, No. 6, 874-879 (Nov.-Dec. 1973).

Key words: Intrinsic viscosity; $\operatorname{poly}(n$-butyl isocyanate); $\operatorname{poly}(n$ octyl isocyanate); rodlike.

Previous calculations of the molecular length of rodlike $\operatorname{poly}(n$ butyl isocyanate), (- $\left.\mathrm{CO}-\mathrm{NC}_{4} \mathrm{H}_{9}-\right)_{n}$, from dielectric relaxation time measurements have not shown satisfactory agreement with the results from x-ray and light-scattering measurements. Here, we examine this conflict by extending our hydrodynamic experiments to include intrinsic viscosity measurements on well-characterized low molecular weight samples of poly( $n$-butyl isocyanate) (PBIC) and poly(n-octyl isocyanate) (POIC), $\left(-\mathrm{CO}-\mathrm{NC}_{8} \mathrm{H}_{17}-\right)_{n}$. Using the Kirkwood-Auer-Riseman equation relating intrinsic viscosity and rod dimensions, the intermonomer translation along the rod axis is calculated to be $1.66 \pm 0.12 \AA$. This is lower than the 1.94 - $\AA$ result from $x$ ray measurements, but higher than the $1.33 \pm 0.12 \AA$ result from dielectric relaxation time measurements. The root of the problem ap- 
pears to be the application of hydrodynamic equations to a physical situation which does not satisfy the model assumptions.

Cameron, J. M., Plumb, H., Traceability - with special reference to temperature measurement, Soc. Automot. Eng. Trans. 78, Section 3, 1586-1590 (1969).

Key words: Calibration; temperature, traceability.

The requirement that measurements be traceable to national standards arose in response to needs for consistency between different parts of the measurement system. There is one single agreed-upon definition for traceability, but it has been taken to mean the existence of some chain of intercomparisons or calibrations leading back to the National Bureau of Standards. Like all procedural or material requirements, its presence or absence may bear little relation to the performance characteristic one is really interested in. The scientific problem of expressing the desired performance requirements in terms of the amount and type of evidence needed to determine the degree of consistency of measurement processes is discussed and illustrated for the measurement of temperature. The importance of the study of measurement as a production process and the need for a program for the surveillance of the measurement process is discussed and plans for a new service for transfer of measurement capability in thermometry are presented.

Carrington, C. G., Drummond, D., Gallagher, A., Phelps, A. V., Oscillations in continuum molecular spectra of alkalimetal-noble-gas molecules, Chem. Phys. Lett. 22, No. 3,511514(Oct. 15, 1973).

Key words: Alkali-metal; continuum; molecules; rare-gas; spectra.

Regular intensity undulations in the continuum spectra of heavy diatomic molecules are reported. In particular, the AII-X $\Sigma$ transition of the $\mathrm{Rb}$ - noble-gas $\mathrm{Cs}$ - noble-gas molecules has been studied. Calculations as well as experimental observations of absorption and emission spectra are reported.

Cassidy, E. C., Anderson, W. E., Booker, S. R., Recent refinements and developments in Kerr system electrical measurement techniques, IEEE Trans. Inst. Meas. IM-21, No. 4, 504-510 (Nov. 1972).

Key words: Electric fields; electrical measurements; electro-optics; high-speed photography; high-speed techniques; high-voltage measurements; Kerr effect; laser applications.

Kerr system electrical measurement techniques are improved by progress in two important areas: 1) in the development of methods for visualizing and measuring pulsed (microsecond) electric fields and high voltages from time-varying electro-optical fringe patterns recorded using high-speed photographic techniques, and 2) in the development of convenient experimental methods for evaluating and correcting path-dependent errors in Kerr system response. Results demonstrate use of fringe-pattern measurements in achieving accurate pulse voltage measurements and in correction of errors resulting from sizeable end-field variations in existing $300-\mathrm{kV}$ Kerr cells.

Cassidy, E. C., Hebner, R. E., Experimental study of the behavior of nitrobenzene under varied high voltage conditions, (Proc. Electrical Insulation and Dielectric Phenomena, Buck Hill Falls, Pa., Oct. 23-25, 1972), Chapter 1972 Annual Report of the Conference Electrical Insulation and Dielectric Phenomena, pp. 37-44 (National Research Council, National Academy of Sciences, Washington, D.C., 1973).

Key words: Dielectric liquid; electrical properties of liquids; electro-optics; high voltage measurement; Kerr effect; laser applications; nitrobenzene; optical properties of liquids.

Recently developed fringe-pattern methods are employed for visualizing time and space variations in electric fields between elec- trodes immersed in nitrobenzene. Investigations are conducted with operation under high direct, pulsed $(\mu \mathrm{s})$, and $60 \mathrm{~Hz}$ voltage. With minimization of effects resulting from variations in the fringing fields at the electrode ends, the fringe-pattern "mappings" of the field distribution enable observation of space-charge behavior. Applied voltages are measured simultaneously using calibrated (with state-of-theart accuracy) devices. Results enable computation and plotting of electric field distribution and intensity, of charge distribution, and of the Kerr constant of nitrobenzene.

Cezairliyan, A., Change in normal spectral emittance (at 650 $\mathbf{n m}$ ) of niobium during melting and its relation to surface roughness, Surface Sci. 40, 429-432 (1973).

Key words: High temperature; melting; niobium; normal spectral emittance; surface roughness.

Investigations on the normal spectral emittance (at $650 \mathrm{~nm}$ ) of niobium during melting are reported. An attempt is made to relate the difference between the emittance of solid and liquid niobium at the melting point to the roughness of the solid surface. The results indicate that this difference is primarily due to conditions of the solid surface.

Chandler, H. H., Bowen, R. L., Paffenbarger, G. C., Mullineaux, A.

L., Clinical evaluation of a radiopaque composite restorative material after three and a half years, J. Dent. Res. 52, No. 5, 1128-1137 (Sept.-Oct. 1973).

Key words: Clinical evaluation; clinical research; composite restorations; dental restorations; dentistry; monomers; operative dentistry; reinforcements.

A clinical comparison was made of an experimental radiopaque composite restorative material and Addent 35. The radiopaque experimental formulation contained a novel ternary eutectic dimethacrylate as the resin binder and fused silica and a novel $\mathrm{BaF}_{2-}$ containing glass as the reinforcing fillers. Evaluation of restorations indicate that the experimental material compared favorably with the commercial material.

Chow, L. C., Brown, W. E., Phosphoric acid conditioning of teeth for pit and fissure sealants, J. Dent. Res. 52, No. 5, 1158 (Sept.-Oct. 1973).

Key words: Enamel; hydroxyapatite; monocalcium phosphate monohydrate; pit and fissure sealant; phosphoric acid.

It is shown that monocalcium phosphate monohydrate, $\mathrm{Ca}\left(\mathrm{H}_{2} \mathrm{PO}_{4}\right)_{2}$ $\cdot \mathrm{H}_{2} \mathrm{O}$, forms on enamel surface during the $\mathrm{H}_{3} \mathrm{PO}_{4}$ conditioning of teeth administered prior to application of pit and fissure sealants. The $\mathrm{Ca}\left(\mathrm{H}_{2} \mathrm{PO}_{4}\right)_{2} \cdot \mathrm{H}_{2} \mathrm{O}$ coating appears to protect teeth from excessive dissolution during the pretreatment and is washed away sub. sequently to provide a clean surface available for adhesion to sealant. These phenomena are in complete accord with the phase diagram for the ternary system $\mathrm{Ca}(\mathrm{OH})_{2} \mathrm{OH}_{3} \mathrm{PO}_{4}-\mathrm{H}_{2} \mathrm{O}$.

Chow, L. C., Brown, W. E., Reaction of dicalcium phosphate dihydrate with fluoride, J. Dent. Res. 52, No. 6, 1220-1227 (Nov.-Dec. 1973).

Key words: Calcium phosphates; dental caries; fluoride; fluorapatite; tooth enamel.

The intermediate formation of $\mathrm{CaHPO}_{4} \cdot 2 \mathrm{H}_{2} \mathrm{O}$ and its subsequent conversion to $\mathrm{Ca}_{5}\left(\mathrm{PO}_{4}\right)_{3} \mathrm{~F}$ or $\mathrm{CaF}_{2}$ may be a major factor in increased fluoride uptake when tooth enamel is pretreated with acid solutions before being exposed to fluoride. To obtain information concerning the form of fluoride incorporation, the reactions of $\mathrm{CaHPO}_{4} \cdot 2 \mathrm{H}_{2} \mathrm{O}$ with solutions containing various amounts of $\mathrm{F}^{-}$and $\mathrm{PO}_{4}{ }^{3-}$ ions were studied.

Clough, S. A., Beers, Y., Klein, G. P., Rothman, L. S., Dipole moment of water from Stark measurements of $\mathrm{H}_{2} \mathrm{O}, \mathrm{HDO}$, and $\mathbf{D}_{2}$ O, J. Chem. Phys. 59, No. 5, 2254-2259 (Sept. 1, 1973). 
Key words: Dipole moment; Stark effect; water.

The equilibrium dipole moment of the water molecule has been determined from Stark effect measurements on two $\mathrm{H}_{2} \mathrm{O}$, one $\mathrm{D}_{2} \mathrm{O}$, and six HDO rotational transitions. The variation of the dipole moment projection operator with rotational state is taken into account and expressions are given for this operator evaluated in the ground vibrational states of the three isotopes. The value obtained for the equilibrium dipole moment is $\left|{ }^{0} \mu_{\chi}\right|=1.8473 \pm 0.0010 \mathrm{D}$. The effective dipole moments in the principal axis energy representation are $\mid \mu_{b}$ $(\mathrm{HOH})|=1.8546 \pm 0.0006 \mathrm{D},| \mu_{b}(\mathrm{DOD}) \mid=1.8558 \pm 0.0021 \mathrm{D}$ and $\mid \mu_{b}$ $(\mathrm{DOH})|=1.7318 \pm 0.0009 \mathrm{D},| \mu_{a}(\mathrm{DOH}) \mid=0.6567 \pm 0.0004 \mathrm{D}$.

Colson, J. P., Reneker, D. H., Growth direction of polyoxymethylene crystals inside irradiated trioxane crystals, $J$. Appl. Phys. 44, No. 10, 4293-4302 (Oct. 1973).

Key words: Electret domains; polyoxymethylene crystals; radiation damage; solid state polymerization; trioxane.

The long slender crystals of polyoxymethylene that grew in irradiated trioxane crystals all grew toward the negative end of the trioxane crystal. The observed direction of growth was consistent with the assumption that the ion at the growing end of the polyoxymethylene chain was a cation. Certain morphological features such as facets and direction of taper of these polyoxymethylene crystals indicated the direction in which the crystals grew. Incidental observations of polyoxymethylene precursor crystals, electret domains in trioxane, and the effects of electron irradiation on polyoxymethylene crystals were made.

Colwell, J. H., Thermal contacts in a low temperature cryostat, Cryogenics 13, No. 11, 674-675 (Nov. 1973).

Key words: Cryogenics; electrical leads; low temperature; thermal conductivity; thermal contact.

The thermal conductances of an assembly used for thermally anchoring electrical leads in a low temperature cryostat are reported. Measurements were made between 0.3 and $4 \mathrm{~K}$ of the conductance across the contacts of miniature gold-plated electrical connectors, insulated copper wires varnished to a copper mounting, and its copper mounting bolted to a copper support.

Cook, R. K., The use of modulated reverberation for measurement of absorption and sound power, (Proc. 1973 National Noise Control Engineering Conf., Washington, D. C., Oct. 15-17, 1973), Paper in Noise-Con 73 Proceedings, D. R. Tree, Ed., pp. 303 308 (Institute of Noise Control Engineering, Noise/News, Poughkeepsie, N.Y., Oct. 1973).

Key words: Noise control; acoustical measurement; sound power.

A source of sound power modulated in amplitude 100 percent at a very low sinusoidal frequency $F$ is introduced into a reverberation chamber. The total acoustical energy in the sound field will have an amplitude modulation at the same frequency $F$, but lagging in phase by $\phi$ due to the absorption in the chamber. An analysis of the differential equation for energy and sound power balance yields (1) the absolute cross-section $A$ for absorption, and (2) the time-averaged absolute sound power $W_{0}$ of the source. Measurements $A$ and $W_{0}$ have been made at various audio frequencies in the $425 \mathrm{~m}^{3}$ reverberation chamber of the Bureau. The modulated source of sound power was electroacoustical-an array of four loudspeakers having their audio input voltage waveforms amplitude-modulated at $F=0.1$ to $0.4 \mathrm{~Hz}$. The sound pressure $\left|p^{2}\right|$ was measured with an array of four microphones. The phase $\phi$ was obtained by means of an analog computer based on a least squares principle of design. For a steady source of sound power, e.g., a noisy machine, a modulated sound field can be produced by modulating (as a function of time) the absorption cross-section of the reverberation chamber. We present the analysis for energy and sound power balance, and examine some methods for achieving modulated absorption cross-sections.
Corley, D. M., Test of a proposed method for vehicle noise measurement, (Proc. 1973 National Noise Control Engineering Conf., Washington, D. C., Oct. 15-17, 1973), Paper in Noise-Con 73 Proceedings, D. R. Tree, Ed., pp. 230-235 (Institute of Noise Control Engineering, Noise/News, Poughkeepsie, N.Y., Oct. 1973).

Key words: Noise source level; sound pressure level; truck tire; directivity.

If a spherical pulsating source radiates into a infinite medium, the sound pressure is inversely proportional to the distance from the source. No real source exactly fulfills these conditions but it is generally assumed that far enough away from the source, spherical spreading will result. It has been proposed [Hixon. Inter-Noise 72 , Washington, D.C.] that a measurement independent of distance results if both sound pressure level and distance from the source are monitored and the sound pressure level is normalized to a constant distance, e.g., 1 meter, from the source. This measurement is deemed Noise Source Level. Data exist for tires which can indicate the merit of this approach [W. Leasure et al, DOT-OST-ONA 71-9]. These data consist of sound pressure level and distance from the source simultaneously monitored as unpowered trucks coast past an array of microphones. The A-weighted Noise Source Level from three types of truck tires with tread designs representative of tread patterns in common use today are presented. It is concluded that spherical spreading is generally not the case even 500 feet from the source. The $\mathrm{r}$-dependence is not satisfactorily removed by this method of analysis. Therefore considerable care should be exercised if Noise Source Level is used to characterize truck tire noise levels. Noise Source Level does appear to be useful for presenting source directivity.

Currie, L. A., The evaluation of radiocarbon measurements and inherent statistical limitations in age resolution, (Proc. 8th International Conference on Radiocarbon Dating, Wellington, New Zealand, Oct. 18-25, 1972), Paper in Proceedings 8th International Conference on Radiocarbon Dating, T. A. Rafter and T. Grant-Taylor, Eds., 2, 598-611 (Royal Society of New Zealand, Wellington, New Zealand, 1973).

Key words: Age resolution; extraneous random errors; factor of merit components; method performance characteristics; minimum and maximum detectable ages; radiocarbon dating; statistical limitations.

A uniform approach, based upon the statistical behavior of random measurement errors, is suggested for assessing the relative merit of alternative methods of measuring radiocarbon and for interpreting and reporting the results of such measurements. The need for an objective, uniform approach is manifest because of the increasing concern with results which are close to the limits of precision or detection of the dating procedures.

The standard deviation of the estimated net signal (sample counts) is first examined in terms of its dependence upon random errors arising in observations of background and gross sample counts. Because of the high precision characterizing such observations, it becomes vital to evaluate random errors additional to the Poisson (counting) errors. The ability to discriminate between samples of similar age, and minimum and maximum detectable ages are discussed in terms of the statistical theory of hypothesis testing. An explicit approach results for the uniform treatment of detection, detectability and age limits.

The performance characteristics of alternative measurement methods cannot simply be stated in terms of a single "figure of merit," because of the rather complex dependence upon counting times, sample, background and modern standard counting rates, and non-Poisson sources of random errors. A "reduced activity" (sample activity/background equivalent activity) plot is offered as a means for planning experiments and for rapidly assessing the capabilities of any specific measurement procedure. As a result of the particular choice of variables for this plot, alternative procedures may be represented 
by points in a fixed, two-dimensional array, where simple translations of the entire array correspond to changes in counting time or sample age.

Davis, D. D., Klemm, R. B., Braun, W., Pilling, M., A flash photolysis-resonance fluorescence kinetics study of ground-state sulfur atoms. II. Rate parameters for reaction of $\mathbf{S}\left({ }^{3} P\right)$ with $\mathbf{C}_{2} \mathbf{H}_{4}$, Int. J. Chem. Kinet. 4, 383-394 (1972).

Key words: Chemistry; ethylene; flash-photolysis; kinetics; resonance-fluorescence; sulfur atoms.

Absolute rate constants for the reaction of $S\left({ }^{3} P\right)$ with ethylene were measured over an ethylene concentration range of 7 , a total pressure of 50 to 400 torr, and a flash intensity range of 10 . At $298{ }^{\circ} \mathrm{K}$, the bimolecular rate constant was found to be invariant over this range of variables and had a measured value of $4.96 \times 10^{-13} \mathrm{~cm}^{3} \mathrm{molec}^{-1} \mathrm{~s}^{-1}$. Over the temperature range of $218^{\circ}$ to $442 \mathrm{~K}$, the rate data could be fit to a simple Arrhenius equation of the form

$$
k_{1}=(7.13 \pm 0.74) \times 10^{-12} \exp \left(\frac{-1.58 \pm 0.08 \mathrm{kcal} / \mathrm{mole}}{R T}\right) .
$$

Units are $\mathrm{cm}^{3}$ molec $^{-1} \mathrm{~s}^{-1}$. The dependence of the measured value of $k_{1}$ on the concentration of the reaction product ethylene episulfide is discussed.

deWit, R., Continuous distribution of disclination loops, Phys. Status Solidi (a) 18, 669-681 (Aug. 1973).

Key words: Burgers vector; continuous defect distribution; disclination; dislocation; distortion elasticity; Frank vector; loop; plasticity.

Kroupa's theory of a continuous distribution of dislocation loops is extended to include disclination loops. The relation of the loop densities to the plastic strain and bend-twist are derived. This provides the connection with the theory of the continuous distribution of dislocations and disclinations. Mura has recently introduced the new concepts of "plastic distortion" and "plastic rotation," and they are identified in this paper as the dislocation- and disclination-loop density tensors. The significance of these quantities for a finite loop is discussed.

Dickens, B., Prince, E., Schroeder, L. W., Brown, W. E., $\mathrm{Ca}\left(\mathrm{H}_{2} \mathrm{PO}_{4}\right)_{2}$, a crystal structure containing unusual hydrogen bonding, Acta Crystallogr. B29, Part 10, 2057-2070 (Oct. 1973).

Key words: Calcium phosphate; centered hydrogen bonds; hydrogen bonding; single crystal neutron diffraction; single crystal x-ray diffraction.

$\mathrm{Ca}\left(\mathrm{H}_{2} \mathrm{PO}_{4}\right)_{2}$ crystallizes in the triclinic unit cell $a=7.5577$ (5), $b=$ 8.2531 (6), $c=5.5504$ (3) $\AA, \alpha=109.87(1)^{\circ}, \beta=93.68(1)^{\circ}$ and $\gamma=$ $109.15(1)^{\circ}$ at $25^{\circ} \mathrm{C}$ with $Z=2$. The structure was determined by an automated $\Sigma_{2}$ method from x-ray data and refined by least-squares analysis to $R_{w}(F)=0.048, R(F)=0.020$ using 3678 observed $\mathrm{x}$-ray data and to $R_{w}(F)=0 \cdot 055, R(F)=0 \cdot 048$ using 843 observed neutron data. Corrections were made for absorption, isotropic secondary extinction and anomalous dispersion in the $\mathrm{x}$-ray case and for anisotropic secondary extinction in the neutron case. Least-squares refinements proceeded to the limits of the data sets in space group $P \overline{\mathrm{l}}$. Rudimentary chains $\mathrm{Ca} \cdots\left[\mathrm{P}(1) \mathrm{O}_{4}\right]-\mathrm{H}(1) \cdots\left[\mathrm{P}(2) \mathrm{O}_{4}\right] \cdots$ run parallel to [1]̄0]. Adjacent chains are joined by $\mathrm{Ca}$... O bonds on one side and by $\mathrm{O}(8)-\mathrm{H}(5)-\mathrm{O}\left(8^{\prime}\right)$ hydrogen bonds on the other. Alternatively, the structure may be considered to contain hydrogen-bonded layers of $\mathrm{PO}_{4}$ groups; these layers are held together by hydrogen bonds on one side and by $\mathrm{Ca} \cdots \mathrm{O}$ bonds on the other. There are two very strong hydrogen bonds in the structure; $\mathrm{O}(7)--\mathrm{H}(4)--0\left(7^{\prime}\right), \mathrm{O}(7) \cdots \mathrm{O}\left(7^{\prime}\right)$ $=2.434(2) \AA$ and $\mathrm{O}(8)--\mathrm{H}(5)--0\left(8^{\prime}\right), \mathrm{O}(8) \cdots \mathrm{O}\left(8^{\prime}\right)=2.423(2) \AA$. These hydrogen bonds join the $\mathrm{P}(2) \mathrm{O}_{4}$ groups together to form and infinite chain. The very strong hydrogen bonds are across nominal centers of symmetry, and diffraction results indicate that each of the $\mathrm{H}(4)$ and $\mathrm{H}(5)$ protons is effectively centered in a broad symmetric potential well, possibly with a central barrier. A combination of diffraction and infrared spectral considerations suggests that the central barriers in the wells, if they exist, probably lie below the zero-point energy of the hydrogens.

Domalski, E. S., Selected values of heats of combustion and heats of formation of organic compounds containing the elements C, H, N, O, P, and S, J. Phys. Chem. Ref. Data 1, No. 2, 221-277 (1972).

Key words: CHNOPS compounds; heat of combustion; heat of formation; selected values.

Selected values of the heats of combustion and heats of formation of 719 organic compounds are reported here. The data tabulated pertain to compounds containing the elements carbon, hydrogen, nitrogen, oxygen, phosphorus, and sulfur (CHNOPS). The information is arranged according to classes of compounds and within each class, compounds are arranged by empirical formula. The general classes covered are: hydrocarbons, alcohols, phenols, polyols, ethers, aldehydes, ketones, acids, acid anhydrides, esters, steroids, lactones, carbohydrates, heterocyclic oxygen compounds, amines, amides, urea derivatives, guanidine derivatives, amino acids, peptides, alkaloids, heterocyclic nitrogen compounds, porphyrins, organic sulfur compounds, and organic phosphorus compounds. When a selection was made from among several investigators, commentary is provided to indicate the choice, and usually some relevant data. The number of references cited is 596. An alphabetical compound index is provided which gives the name, page number, empirical formula, and the Wiswesser Line Notation (WLN), for each compound.

Drullinger, R. E., Zare, R. N., Optical pumping of molecules II. Relaxation studies, J. Chem. Phys. 59, No. 8, 4225-4234 (Oct. 15, 1973).

Key words: Molecules; optical pumping.

The $\left(v^{\prime \prime}=3, J^{\prime \prime}=43\right)$ level of $\mathrm{Na}_{2}$ has been optically aligned using the 4880 - $\AA$ line of a cw argon ion laser as a light source. The relaxation of this alignment is measured upon addition of foreign gas. In a low-pressure regime, where the mean free path exceeds the diameter of the light beam which both pumps and samples the alignment, the relaxation of the alignment versus pressure shows a "dog-leg shape" consisting of two linear regions. The first linear region corresponds to both elastic (velocity-changing) and inelastic (primarily rotational transfer) collisional relaxation whereas the second corresponds purely to inelastic collisional relaxation. The former process is dependent on the mode structure of the laser and shows saturation with increased pressure. In this low-pressure regime, the measured cross sections are shown to be lower bounds to the true cross sections and excitation by a multimode laser is shown to be inequivalent to excitation by a white light source when the width of the holes in the velocity distribution of the absorber molecules are nonoverlapping.

Erez, A., Low-frequency electrical signal measurement by electrooptical methods, IEEE Trans. Instr. Meas. IM-21, No. 4, 358-360 (Nov. 1972).

Key words: Electrooptical coupling; feedback amplifiers; light emitting diodes; photodetectors.

An analog system for the optical telemetry of voltage or current information using light-emitting diodes (LED) is described. Errors resulting from variations in the optical coupling efficiency are minimized because the light emitted by the LED contains the signal to be measured superimposed on a fixed intensity beam controlled by a reference zener diode. The nonlinearity of the LED is overcome by using part of its emitted light to control the feedback current of an operational amplifier that supplies the signal to the LED. The prototype system developed has a total error of approximately 0.2 percent of the input signal. 
Ferguson, E. E., Fehsenfeld, F. C., Phelps, A. V., Comment on photodetachment cross sections for $\mathrm{CO}_{3}{ }^{-}$and its first hydrate, J. Chem. Phys. 59, No. 3, 1565-1566 (Aug. 1, 1973).

Key words: $\mathrm{CO}_{3}{ }^{-}$; negative ions; photodetachment cross section; photodissociation.

Burt recently reported the photodetachment threshold energies for $\mathrm{CO}_{3}{ }^{-}+h v \rightarrow \mathrm{CO}_{3}+e$ and $\mathrm{CO}_{3}{ }^{-} \cdot \mathrm{H}_{2} \mathrm{O}+h v \rightarrow \mathrm{CO}_{3} \cdot \mathrm{H}_{2} \mathrm{O}+e$ to be 1.8 and $2.1 \mathrm{eV}$, respectively. It can be shown from previously established thermochemistry that these reported threshold energies are substantially too low unless the dissociation energy $D\left(\mathrm{CO}_{2}-\mathrm{O}\right)$ is much larger $(>1.5 \mathrm{eV})$ than has been previously reported.

Flatto, L., Haber, S., A quadrature formula of degree three, $J$. Approximation Theory 9, No. 1, 44-52 (Sept. 1973).

Key words: Hilbert basis; integration; invariants; multiple integrals; numerical integration; quadrature; reflection groups; symmetric groups; symmetries.

Let $R$ be a region in $n$-space and $Q$ a linear quadrature formula for $R$ of the form

$$
Q(f)=\sum_{r=1}^{k} a_{r} f\left(x_{r}\right) .
$$

It is known that if $Q(f)=\int_{R} f$ whenever $f$ is a polynomial of degree 3 or lower, then $k \geqslant n+1$. It is known that the minimum possible value of $k$ depends on the region $R$, being $2 n$ for the $n$-cube and $n+2$ for the $n$-simplex $(n>1)$. In 1956 Hammer and Stroud conjectured that $k \geqslant n$ +2 for every $R$, when $n>1$. In this paper we construct an $R$, and a $Q$ with the required property, with $k=n+1$.

Flynn, D. R., Leasure, W. A., Jr., Machinery noise: Measurement standards and test codes, (Proc. 1973 National Noise Control Engineering Conf., Washington, D.C., Oct. 15-17, 1973), Paper in Noise-Con 73 Proceedings, D. R. Tree, Ed., pp. 257-260 (Institute of Noise Control Engineering, Noise/News, Poughkeepsie, N.Y., Oct. 1973).

\section{Key words: Acoustics; noise; soundpower.}

Measurements of the sound power emitted by machinery, or of the sound pressure at specific locations, are needed for a variety of purposes. These include measurements for diagnostic and control purposes, measurements for labeling (explicitly or implicitly) the noise emission from a product, and measurements to determine compliance with specifications or regulations. A brief discussion is given of the general items which should be included in noise measurement standards and test codes. An example of standards addressing these points is the series of basic documents on sound power level measurements being prepared under the auspices of the International Organization for Standardization.

Gubser, D. U., Soulen, R. J., Jr., Thermodynamic properties of superconducting iridium, J. Low Temp. Phys. 13, No. 3/4, 211226 (1973).

Key words: Critical magnetic field; iridium; superconductivity; transition temperatures.

The superconducting transition temperature of pure Ir is found to be $0.1125 \mathrm{~K}( \pm 0.0005 \mathrm{~K})$. The critical magnetic field as a function of temperature $\mathrm{H}_{c}(\mathrm{~T})$ has also been measured. From these data it is determined that $\mathrm{H}_{c}(\mathrm{O})$ is $16.00 \mathrm{G}$ ( $1 \mathrm{G}$ corresponds to $\left.10^{-4} \mathrm{~T}\right)$, $\left(\mathrm{dH}_{c} / \mathrm{dT}\right)_{T=T c}$ is $235 \mathrm{G} / \mathrm{K}$, the linear coefficient of normal state electronic specific heat $\gamma$ is $3.19 \mathrm{~mJ} / \mathrm{mole}-\mathrm{K}^{2}$, and the energy gap anisotropy parameter $\left\langle a^{2}\right\rangle$ is 0.048 . This value for $\left\langle a^{2}\right\rangle$ is the largest of any superconducting element so far observed, and its significance in determining the superconducting properties of Ir is discussed. By using the large supercooling effects noticed near $\mathrm{T}_{c}$, the GinzburgLandau parameter $\chi_{0}$ is found to be $8.6 \times 10^{-3}$. The effects of impurities on $\mathrm{T}_{c}$ and on the magnetic behavior of $\mathrm{Ir}$ are also discussed.
Haber, S., Shisha, O., An integral related to numerical integration, Bull. Amer. Math. Soc. 79, No. 5, 930-932 (Sept. 1973).

Key words: Bounded variation; improper integral; monotonicity; numerical integration; quadrature; Reimann integral.

The question of the convergence of numerical integration formulas (of Riemann sum type) to the improper Riemann integral $\int_{0}^{\infty} f(x) d x$ is studied. A new integral over $[0, \infty)$, more restrictive than the improper Riemann integral but not absolutely convergent, is introduced. Necessary and sufficient conditions are found for a function to be integrable in the new sense; they are stated in terms of property of functions similar to the property of being of bounded variation. A convergence theorem for the numerical integration of such functions is given.

Hamer, W. J., W u, Y-C., Osmotic coefficients and mean activity coefficients of uni-univalent electrolytes in water at $25{ }^{\circ} \mathrm{C}$, J. Phys. Chem. Ref. Data 1, No. 4, 1047-1099 (1972).

Key words: Activity coefficients; activity coefficients of uniunivalent electrolytes; excess Gibbs energy for electrolytes; experimental methods for determining activity coefficients; osmotic coefficients.

This paper gives values for the osmotic coefficients and mean activity coefficients of uni-univalent electrolytes in aqueous solutions at $25{ }^{\circ} \mathrm{C}$. The values are expressed on the molality or weight basis. Literature data have, for the most part, been critically evaluated through the excess Gibbs energy, $\Delta G^{e x}$, which relates the osmotic coefficient, $\phi$, and the mean activity coefficient, $\gamma$, by the expression: $\Delta \mathrm{G}^{e x}=2 \mathrm{~m} \mathrm{R} \mathrm{T}(1-\phi+\ln \gamma)$ where $\mathrm{m}$ is molality, $\mathrm{R}$ the gas constant, and $\mathrm{T}$ the Kelvin temperature. General relations for chemical potentials, activities, activities coefficients and osmotic coefficients are presented and five experimental methods for determining activity coefficients are described.

Hampson, R. F., Editor, Braun, W., Brown, R. L., Garvin, D., Herron, J. T., Huie, R. E., Kurylo, M. J., Laufer, A. H., McKinley, J. D., Okabe, H., Scheer, M. D., Tsang, W., Stedman, D. H., Survey of photochemical and rate data for twenty-eight reactions of interest in atmospheric chemistry, J. Phys. Chem. Ref. Data 2, No. 2, 267-311 (1973).

Key words: Atmospheric chemistry; chemical kinetics; data evaluation; gas phase reactions; optical absorption coefficients; photochemistry; quantum yields; rate constants.

Photochemical and rate data have been evaluated for twenty-eight gas phase reactions of interest for the chemistry of the stratosphere. The results are presented on data sheets, one per reaction. For each reaction, the available data are summarized. Where possible there is given a preferred value for the rate constant or, for the photochemical reactions, preferred values for primary quantum yields and optical absorption coefficients.

Hanley, H. J. M., Prydz, R., The viscosity and thermal conductivity coefficients of gaseous and liquid fluorine, J. Phys. Chem. Ref. Data 1, No. 4, 1101-1113 (1972).

Key words: Fluorine; kinetic theory; modified Enskog Theory; thermal conductivity; viscosity.

Tables of values for the viscosity and thermal conductivity of fluorine are presented in the range $70-300 \mathrm{~K}$ for pressures up to 200 atmospheres. Dilute gas values were determined from Kinetic Theory using the m-6-8 potential. Dense gas and liquid values were obtained from the modified Enskog Theory. The critical point anomoly in the thermal conductivity coefficient is also discussed.

Hardy, S. C., Coriell, S. R., Surface tension and interface kinetics of ice crystals freezing and melting in sodium chloride solutions, J. Cryst. Growth 20,292-300 (1973). 
Key words: Crystal growth; ice; interface kinetics; morphological stability; sodium chloride; surface tension.

Cylindrical ice crystals growing into supercooled $0.1 \mathrm{M}$ sodium chloride solutions develop approximately sinusoidal perturbations parallel to the cylinder axis. Using a previously developed non-linear morphological stability theory, an analysis of the growth and melting rates of these perturbations yields values of the solid-liquid surface tension and linear interface kinetic coefficient. In contrast to previous results in $0.1 \mathrm{M}$ hydrochloric acid solutions, the melting behavior in sodium chloride solutions is different from the growth behavior. From the growth data, the solid-liquid surface tension is $30 \mathrm{~mJ} / \mathrm{m}^{2}$ and the linear interface kinetic coefficient is $2.2 \times 10^{-4} \mathrm{~m} / \mathrm{s} \mathrm{K}$ for solutions with $\mathrm{pH}>6$. For solutions with $\mathrm{pH}<5.5$ and for all solutions on melting, the kinetic coefficients is too large $\left(>10^{-3} \mathrm{~m} / \mathrm{s} \mathrm{K}\right)$ to measurably affect the perturbation velocities. From the melting data, the surface tension is $38 \mathrm{~mJ} / \mathrm{m}^{2}$. The difference in surface tension on melting and growth is attributed to ionic adsorption during growth. Experiments in which the crystal is grown in one solution and is melted in a different solution indicate that the surface tension depends on the chloride content of the ice.

Haynes, W. M., Viscosity of gaseous and liquid argon, Physica 67, No. 3, 440-470 (Aug. 1973).

Key words: Argon; compressed gas and liquid; dilute gas; saturated liquid; torsional crystal viscometer; viscosity.

The coefficient of shear vicosity of fluid argon has been measured at temperatures from 85 to $298 \mathrm{~K}$ and at pressures up to $34 \mathrm{MN} / \mathrm{m}^{2}$ using the torsional crystal viscometer. The precision and accuracy of these measurements were estimated to be 0.5 and 2 percent, respectively. A detailed description of the apparatus and experimental measuring techniques is presented. Viscosity data for the compressed gas were represented and analyzed using density expansions. An empirical relation was developed to represent the data over the entire fluid range as a function of density and temperature. Also included is a comprehensive comparison of the present results with previous experimental data and theoretical predictions.

Hayward, E., Barber, W. C., Sazama, J., Nuclear scattering of plane-polarized photons, Phys. Rev. C8, No. 3, 1065-1073 (Sept. 1973).

Key words: Dynamic collective model; giant resonance; nuclear surface oscillations; photon scattering; polarized photons; tensor polarizability.

A beam of plane-polarized monochromatic photons has been produced by the resonance fluorescence of the well-known $1^{+}$state at $15.1 \mathrm{MeV}$ in ${ }^{12} \mathrm{C}$. These have been scattered a second time from natural targets of $\mathrm{Cd}, \mathrm{Sn}, \mathrm{Ta}, \mathrm{W}, \mathrm{Pt}, \mathrm{Au}$, and $\mathrm{Bi}$. Measurements were made with poor energy resolution of the relative number of photons scattered at $90^{\circ}$ parallel and perpendicular to the polarization vector in the incident $15.1-\mathrm{MeV}$ beam. The observation of photons scattered along the polarization vector reflects the contribution of incoherent scattering to the dominant coherent-scattering process and results either from permanent nuclear deformation or from the dynamic deformation produced by the coupling of the giant dipole resonance with the quadrupole oscillations of the nuclear surface. The observed intensities of incoherent scattering are of the same order of magnitude for the deformed nuclei and the spherical vibrators and agree roughly with the predictions of the dynamic collective model. No incoherent scattering was observed from the rigid sphere ${ }^{209} \mathrm{Bi}$.

Hebner, R. E., Jr., Cassidy, E. C., Measurement of $60 \mathrm{~Hz}$ voltages using the Kerr effect, Rev. Sci. Instrum. 43, No. 12, 1839 1841 (Dec. 1972).

Key words: Electrical measurements; electro-optics; high voltage measurements; Kerr effect; laser applications; optical techniques.

The Kerr effect has been used to measure $60 \mathrm{~Hz}$ alternating voltage up to $30 \mathrm{kV}$ peak. The system behaves much as it does under the influence of a short high-voltage pulse except that in this case the frequency of the applied voltage is sufficiently low that the space charge effects in the liquid are not negligible.

Helminger, P., De Lucia, F. C., Kirchhoff, W. H., Microwave spectra of molecules of astrophysical interest. IV. Hydrogen sulfide, J. Phys. Chem. Ref. Data 2, No. 2, 215-223 (1973).

Key words: Hydrogen sulfide; hyperfine structure; interstellar molecules; microwave spectra; molecular parameters; radio astronomy; rotational transitions.

The available data on the microwave spectrum of hydrogen sulfide are critically reviewed for information applicable to radio astronomy. Molecular data such as rotational constants, centrifugal distortion constants, hyperfine coupling parameters, and dipole moments are tabulated. A detailed centrifugal distortion calculation has been carried out for the most abundant isotopic form of this molecule, $\mathrm{H}_{2}{ }^{32} \mathrm{~S}$, as well as for $\mathrm{HD}^{32} \mathrm{~S}$. Transitions have been predicted and tabulated for the frequency range $1 \mathrm{MHz}$ to $1000 \mathrm{GHz}$ for $\mathrm{H}_{2}{ }^{32} \mathrm{~S}$ and $1 \mathrm{MHz}$ to $700 \mathrm{GHz}$ for $\mathrm{HD}^{32} \mathrm{~S}$. All predicted transitions include 95 percent confidence limits; estimated error limits have been reported for all measured transitions. Observed transitions of $\mathrm{H}_{2}{ }^{33} \mathrm{~S}$ and $\mathrm{H}_{2}{ }^{34} \mathrm{~S}$ are also listed.

Hougen, J. T., A modified ladder operator formalism for molecule-fixed components of the total angular momentum operator in linear molecules, J. Mol. Spectrosc. Notes $\mathbf{4 8}$, No. 3, 609-611 (Dec. 1973).

Key words: Commutation relations; Eulerian angles; ladder operators; linear molecules; molecule-fixed components; total angular momentum.

Because molecule-fixed components of the total angular momentum operator for linear molecules do not obey angular momentum commutation relations (either with or without the anomalous sign of $i$ ), the traditional angular momentum ladder operator formalism cannot be applied. It is known that this difficulty can be overcome by introducing into the linear molecule problem an extra rotational angle, which has no physical significance, but which does lead to a formalism isomorphic with the normal formalism for nonlinear molecules. It is shown that the linear molecule angular-momentum problem is susceptible to treatment, without introduction of an extraneous variable, by a relatively straightforward extension of the conventional formalism, in which angular momentum operators are taken to be functions of an integral or half-integral parameter representing the projection of the total angular momentum along the linear axis.

Hummer, D. G., Seaton, M. J., Interpretation of the spectra of planetary nebulae. Introductory Report, Mem. Soc. Roy. Sci. Liege V, 225-238 (1973).

Key words: Forbidden lines; nebular spectra; planetary nebulae; recombination spectra.

Progress since 1967 in the interpretation of nebular spectra is reviewed.

Hunt, C. M., An analysis of roll filter operation based on panel filter measurements, ASHRAE Trans. 78, Part 2, 227-234 (1972).

Key words: Air conditioning filters; air filters; particulate filters; roll filters.

The pressure drop across an air filter can usually be expressed as a linear function of the face velocity in a log-log plot. This is true for both clean and dirty filters. Use of this fact has been made to develop a descriptive model to predict the dust holding capacity of a roll filter from parameters measured with a panel filter of the same medium when the movement of the roll filter is controlled by a pressure switch. The model is applied to some test data obtained with a panel filter to explore the possible effect of varying pressure switch 
settings, air velocity, and other parameters on the predicted performance of a roll filter.

Iverson, W. P., The corrosion of mild steel by a marine strain of Desulfovibrio, (Proc. 3d Int. Congress on Marine Corrosion and Fouling, Gaithersburg, Md., Oct. 2-6, 1972), Paper in Proceedings: Third International Congress on Marine Corrosion and Fouling, pp. 61-82 (Northwestern University Press, Evanston, Ill., Oct. 1973).

Key words: Anaerobic corrosion; depolarizing agent; ferrous ions; marine corrosion; marine Desulfovibrio; polarization techniques.

A marine strain of Desulfovibrio was isolated from steel piling detritus at Dam Neck, Va. A medium which provided good surface growth on 2 percent agar plates in a hydrogen atmosphere was developed (Trypticase, 15 gm; Phytone, 5 gm; NaCl, 5 gm; seawater, $1000 \mathrm{ml}$ ). The corrosion rate of mild steel in this medium, with and without the addition of $\mathrm{Fe}^{++}$ions, was investigated using polarization techniques. In the absence of added $\mathrm{Fe}^{++}$ions, the corrosion rate was found to decrease and then either increase or remain at a low level. In one corrosion cell a high rate of corrosion was accompanied by the formation of a corrosion product or products in the shape of "stalactite" formations. Analysis indicated free sulfur and an iron sulfur compound with iron in the $\mathrm{Fe}^{+++}$state.

In the presence of added $\mathrm{Fe}^{++}$ions, the corrosion rate was found to increase to $255 \mathrm{mdd}$ in one corrosion cell and then decrease. Chemically prepared $\mathrm{FeS}$ produced little change in the potential or the corrosion rate. Corrosion of mild steel in a bacteria-free culture filtrate, to which $\mathrm{Fe}^{++}$ions were added in excess to remove the $\mathrm{S}^{=}$ions was extremely high. After an induction period of 3 days, the corrosion rate increased to a maximum of 1130 mdd 8 days after the start of the corrosion process. During the period of extensive corrosion, the potential of the steel dropped to more noble values.

When the black precipitate, formed upon the addition of $\mathrm{Fe}^{++}$ions, was removed, the resulting filtrate was still highly corrosive, indicating that the depolarizing agent was water soluble and not the precipitate. The depolarizing agent appears to act as an electron carrier, removing electrons from the iron and transferring them to an acceptor which is thereby reduced. The action of this depolarizing agent could account for the high anaerobic corrosion rates observed in the field.

Inhibition of corrosion in cultures of Desulfovibrio appears to be due to the action of $\mathrm{H}_{2} \mathrm{~S}$ which reacts with the iron to form a protective film and prevents the actions of the soluble depolarizer.

Jacob, E. J., Lide, D. R., Jr., Structural implications of the microwave spectrum of hexafluoropropene, J. Chem. Phys. 59, No. 11, 5877-5881 (Dec. 1, 1973).

Key words: Ground vibrational state; microwave spectrum of hexafluoropropene; rotational constants.

Analysis of the microwave spectrum of hexafluoropropene, $\mathrm{C}_{3} \mathrm{~F}_{6}$, has yielded rotational constants for the ground vibrational state of 2557.88, 1255.033, and 987.082 MHz. Assignments have also been made on the first four excited states of the $\mathrm{CF}_{3}$ torsional mode and on the first excited state of another low-lying skeletal mode. A rough estimate of $350 \mathrm{~cm}^{-1}$ has been obtained for the barrier to internal rotation of the $\mathrm{CF}_{3}$ group. The ground-state moments of inertia are consistent with the expected geometry of the molecule, in which all atoms are coplanar except for two equivalent $\mathrm{F}$ atoms in the $\mathrm{CF}_{3}$ group.

Jacox, M. E., Milligan, D. E., Matrix-isolation study of the reaction of $\mathrm{H}$ atoms with $\mathrm{NO}$. The infrared spectrum of $\mathrm{HNO}, J$. Mol.Spectrosc. 48, No. 3, 536-559 (Dec. 1973).

Key words: Force constants; $\mathrm{H}+\mathrm{NO}$ reaction; HNO; infrared spectrum; matrix isolation; thermodynamic properties.
Studies of the reaction with NO in an argon or a nitrogen matrix at $4^{\circ}$ or $14 \mathrm{~K}$ of $\mathrm{H}$ and $\mathrm{D}$ atoms produced either photolytically or in a microwave discharge have confirmed the previous identification of the ground-state NO stretching fundamental of $\mathrm{HNO}$ and of DNO but have dictated a reassignment of the deformation fundamental of these two species. An absorption at $1153 \mathrm{~cm}^{-1}$ has been assigned as the deformation fundamental of DNO, and evidence is presented suggesting that the deformation fundamental of HNO lies very close to $1500 \mathrm{~cm}^{-1}$. The assignment of an absorption at $2717 \mathrm{~cm}^{-1}$ as the NH stretching fundamental of $\mathrm{HNO}$ and of an absorption at $2043 \mathrm{~cm}^{-1}$ as the corresponding fundamental of DNO is consistent with the previous report of an exceptionally long NH bond for ground-state HNO. Detailed isotopic studies support this revised vibrational assignment, which is shown to be consistent with previous gas-phase studies. The force constants and thermodynamic properties of ground-state $\mathrm{HNO}$ derived from the matrix data are presented.

Jennings, D. A., Braun, W., Broida, H. P., Vibrational relaxation of hydrogen by direct detection of electronic and vibrational energy transfer with alkali metals, J. Chem. Phys. 59, No. 8, 4305-4308 (Oct. 15, 1973).

Key words: Apparatus; energy transfer; metals; method; photochemistry; resonance fluorescence; vibrational relaxation.

A technique has been developed to measure the rate constant for vibrational relaxation of $\mathrm{H}_{2}{ }^{v}=3,4$ by $\mathrm{H}_{2} v=0$. The technique uses a mechanically chopped, tunable, cw dye laser coincident with either of the Na resonance lines at 589.6 or $589.0 \mathrm{~nm}$. Sodium vapor is contained in a glass cell along with $\mathrm{Cs}$ atoms and $\mathrm{H}_{2}$. Sodium atoms, excited by the dye laser radiation, collisionally transfer electronic energy to $\mathrm{H}_{2}$ producing some $\mathrm{H}_{2}{ }^{v}$. Only vibrational energy in $\mathrm{H}_{2}{ }^{v}$ from levels $v=3,4$ can transfer to $\mathrm{Cs}$ as electronic energy and cause Cs resonance line emission at 894 and $852 \mathrm{~nm}$. In this manner, using the observed emission as a detector of $\mathrm{H}_{2} v=3,4$, the vibrational relaxation rate constant was determined to be $3.9 \times 10^{-14} \mathrm{~cm}^{3} \mathrm{sec}^{-1}$. Similar rate constants were measured, with somewhat less accuracy, for $\mathrm{D}_{2}{ }^{v}$ colliding with $\mathrm{D}_{2}$ and for $\mathrm{H}_{2}{ }^{v}$ colliding with $\mathrm{He}$. It was found that $\mathrm{N}_{2}$, $\mathrm{Na}$, and $\mathrm{Cs}$ also undergo electronic to vibration and vibration to electronic energy exchange.

Johnson, C. R., A Geršgorin inclusion set for the field of values of a finite matrix, Proc. Amer. Math. Soc. 41, No. 1, 57-60 (Nov. 1973).

Key words: Eigenvalues; field of values; Geršgorin set; numerical radius; spectrum; subadditive set valued function.

An easily computed Geršgorin type inclusion set for the field of values of an $n$ by $n$ complex matrix is presented. Some functional properties of this inclusion set parallel those of the field of values, and illustrative examples are given.

Johnson, D. R., Lovas, F. J., Kirchhoff, W. H., Microwave spectra of molecules of astrophysical interest. I. Formaldehyde, formamide, and thioformaldehyde, J. Phys. Chem. Ref. Data 1, No. 4, 1011-1045 (1972).

Key words: Formaldehyde; formamide; interstellar molecules; microwave spectra; molecular parameters; radio astronomy; rotational transitions.

The available data on the microwave spectrum of formaldehyde, formamide, and thioformaldehyde is critically reviewed for information applicable to radio astronomy. Molecular data such as rotational constants, centrifugal distortion parameters, dipole moments, hyperfine coupling constants, and structural parameters are tabulated. $\mathrm{Ob}$ served rotational transitions are presented for the astronomically interesting isotopic forms of these molecules when available. Detailed centrifugal distortion calculations have been carried out for the most abundant isotopic forms of these molecules, namely, $\mathrm{H}_{2}{ }^{12} \mathrm{C}^{16} \mathrm{O}$, $\mathrm{H}_{2}{ }^{13} \mathrm{C}^{16} \mathrm{O},{ }^{14} \mathrm{NH}_{2}{ }^{12} \mathrm{CH}^{16} \mathrm{O}$, and $\mathrm{H}_{2}{ }^{12} \mathrm{C}^{32} \mathrm{~S}$. Transitions have been predicted and tabulated for the frequency ranges 
$1 \mathrm{MHz}$ to $300 \mathrm{GHz}$ for $\mathrm{H}_{2}{ }^{12} \mathrm{C}^{16} \mathrm{O}$,

$100 \mathrm{MHz}$ to $300 \mathrm{GHz}$ for $\mathrm{H}_{2}{ }^{13} \mathrm{C}^{16} \mathrm{O}$,

$500 \mathrm{MHz}$ to $180 \mathrm{GHz}$ for ${ }^{14} \mathrm{NH}_{2}{ }^{12} \mathrm{CH}^{16} \mathrm{O}$,

and

$100 \mathrm{MHz}$ to $300 \mathrm{GHz}$ for $\mathrm{H}_{2}{ }^{12} \mathrm{C}^{32} \mathrm{~S}$.

All predicted transitions include 95 percent confidence limits; measured transition error limits have been reproduced from the original literature. References are given for all data included.

Johnson, V. J., Thermodynamic and transport properties of cryogenic propellants and related fluids, (Proc. American Society for Testing and Materials Symp. on Cryogens and Gases: Testing Methods and Standards Development, Los Angeles, Calif., June 25-30, 1972), Amer. Soc. Test. Mater. Spec. Tech. Publ. 537, pp. 64-78 (1973).

Key words: Argon; bibliography; compilations; critical evaluation; cryogens; experimental measurement; fluorine; helium; hydrogen; methane; nitrogen; oxygen; properties of fluids; review; thermodynamic.

Significant advances have been made in recent years in the quality and range of thermophysical data for the cryogenic propellants, pressurants, and inertants. These advances have resulted from improved evaluation and compilation techniques coupled with better and more extensive experimental data and from a better theoretical understanding of the physical properties of gases. A review of recently completed and current data compilation projects for helium, hydrogen, argon, nitrogen, oxygen, fluorine, and methane will be given as well as recommended references for thermodynamic and transport property data tables for these fluids. Modern techniques in the plotting of thermodynamic charts from tabular data (or from functions such as the equation of state) have greatly improved their precision and value. A list of such charts is included.

Julienne, $\mathrm{P}$. S., Nonadiabatic effects in the $B, C, B^{\prime}$, and $D$ states of $\mathbf{H}_{2}$, J. Mol. Spectrosc. 48, No. 3, 508-529 (Dec. 1973).

Key words: $\Lambda$-doubling; heterogeneous interaction; molecular hydrogen; nonadiabatic; pure precession; RKR potentials.

The Kolos-Wolniewicz potentials for the $\mathrm{H}_{2} B^{1} \Sigma_{u}{ }^{+}$and $C^{1} \Pi_{u}$ states were used together with the hypothesis of pure precession for the rotation-electronic interaction, to calculate the nonadiabatic energy levels of these states for $J=1$ to 5 . The complete coupling matrix was computed using accurate numerical vibrational wavefunctions. The calculated $\Lambda$-doubling of the $v=0$ to $12 C$ vibrational levels generally agrees well with experimental values, and the nonadiabatic shifts in the $B$ rotational constants qualitatively explain the difference between the theoretical and RKR potentials for this state.

The interaction of the $B^{\prime}{ }^{1} \Sigma_{u}{ }^{+}$and $D{ }^{1} \Pi_{u}$ states was also investigated, but only qualitatively since adiabatic potentials of sufficient accuracy do not exist for these states. The $\Lambda$-doubling of the $D v$ $=0$ rotational levels agrees well with the experimental values. An appreciable "background" nonadiabatic shift in the $\boldsymbol{B}^{\prime}$ rotational constants was found. This shift, which is nearly 5 percent of $B_{v}$, is in addition to that of strong local two-level interactions and was not "deperturbed" in constructing the $B^{\prime}$ RKR potential. The result is that the RKR turning points differ by about 0.04 au from the "true" adiabatic turning points. This conclusion is supported by a HartreeFock calculation of the $B^{\prime}$ potential to the left of $R_{e}$.

Kearsley, E. A., Measurement of normal stress by means of hole pressure, Trans. Soc. Rheol. 17, No. 4, 617-628 (1973).

Key words: Hole pressure; normal stress; pressure hole errors; shearing flows.

A measurement of normal stress differences in a shearing elastic liquid is accomplished through direct measurement of hole pressure. Gravity flow down an inclined channel is used and hole pressure is measured for slots perpendicular and parallel to the flow, as well as for a circular hole. The first and second normal stress differences are calculated under the assumption of second-order fluid behavior. Dynamic data are compared and a discrepancy noted.

Keller, R. A., Tunable lasers for chemists, Chem. Technol., 626634 (Oct. 1973)

Key words: Dye laser; isotope separation; photochemistry; review; saturation spectroscopy; spectroscopic analysis.

A general review of organic dye lasers and their use in the fields of: analytical chemistry, chemical synthesis and separation, photobiology, and spectroscopy is presented. The text includes 47 references.

Keller, R. A., Simmons, J. D., Jennings, D. A., Enhancement of absorption spectra by dye-laser quenching, III: Quantitative aspects and a comparison of flash-lamp-pumped and $\mathrm{cw}$ systems under high resolution, J. Opt. Soc. Amer. 63, No. 12, 1552-1555 (Dec. 1973).

Key words: Dye laser; intra-cavity absorption; iodine detection; laser quenching; trace absorption detection; visible molecular absorption.

The enhancement of the detectability for trace absorptions by placing samples inside the laser cavity was found to be a factor of 100 for a flash-lamp-pumped dye laser and one thousand for a cw dye laser. High-resolution spectra showed that the holes in the laser output were as narrow as the absorptions that caused them. An approximately linear relationship (rather than the step-function behavior often associated with threshold phenomena) exists between pressures necessary to produce visually identical absorption spectra from samples placed inside and outside of the laser cavity. If such a relationship is of general occurrence, it will greatly facilitate the use of intracavity absorption for quantitative analysis, determination of relative absorption cross section, and for the study of the kinetics of appearance and disappearance of transient species.

Kirchhoff, W. H., Johnson, D. R., Lovas, F. J., Microwave spectra of molecules of astrophysical interest II. Methylenimine, J. Phys. Chem. Ref. Data 2, No. 1, 1-10 (1973).

Key words: Hyperfine structure; interstellar molecules; methylenimine; microwave spectra; molecular parameters; radio astronomy; rotational transitions.

The available data on the microwave spectrum of methylenimine are critically reviewed for information applicable to radio astronomy. Molecular data such as rotational constants, centrifugal distortion parameters, hyperfine coupling constants, and dipole moments are tabulated. A detailed centrifugal distortion calculation has been carried out for the most abundant isotopic form of this molecule, $\mathrm{H}_{2}{ }^{12} \mathrm{C}^{14} \mathrm{NH}$. Transitions have been predicted and tabulated for the frequency range $100 \mathrm{MHz}$ to $300 \mathrm{GHz}$. All predicted transitions include 95 percent confidence limits; error limits have been reported for all measured transitions.

Kirchhoff, W. H., Johnson, D. R., Powell, F. X., Centrifugal distortion effects in $\mathrm{SF}_{2}$ : Calculation of the force field and infrared spectrum, J. Mol. Spectrosc. 48, No. 1, 157-164 (Oct. 1973).

Key words: Centrifugal distortion; force field; microwave spectrum; $\mathrm{SF}_{2}$; structure; vibrational fundamental.

Measurements of the microwave spectrum of $\mathrm{SF}_{2}$ have been extended up to $J=43$ in order to account for the effects of centrifugal distortion. Seventy-five transitions have been included in a weighted least squares fit of the measured spectrum with an rms deviation of $0.078 \mathrm{MHz}$. The force field for $\mathrm{SF}_{2}$ has been determined from the centrifugal distortion constants. The vibrational spectrum, as yet unob- 
served, has been predicted from the force field as have been the Coriolis coupling constants and the average structure.

Krupenie, P. H., The spectrum of molecular oxygen, J. Phys. Chem. Ref. Data 1, No. 2, 423-534 (1972).

Key words: Molecular oxygen; molecular spectrum; review.

This is a critical review and compilation of the observed and predicted spectroscopic data on $\mathrm{O}_{2}$ and its ions $\mathrm{O}_{2}{ }^{-}, \mathrm{O}_{2}{ }^{+}$, and $\mathrm{O}_{2}{ }^{2+}$. The literature survey upon which it is based was terminated in February 1971.

Leasure, W. A., Jr., Au tomobile tire noise: A review of the open literature, (Proc. 1973 National Noise Control Engineering Conf., Washington, D.C., Oct. 15-17, 1973), Paper in Noise-Con 73 Proceedings, D. R. Tree, Ed., pp. 187-195 (Institute of Noise Control Engineering, Noise/News, Poughkeepsie, N.Y., Oct. 1973).

Key words: Acoustics; automobile; noise (sound); tire noise; transportation noise.

Automobiles, the primary mode of transportation in the United States, contribute significantly to the noise environment due to the large number in operation. In this paper, one aspect of automobile noise is discussed, namely the contribution to overall vehicle noise made by the interaction of the tires with the road surface. For passenger cars, tire noise can be a significant contributor to overall levels at speeds as low as $35-40 \mathrm{mph}$ and typically is the major contributor at higher speeds. Based on the limited data base available in the open literature, a discussion is given of the effects of various vehicle operational modes, tire mechanical properties, and road surface texture on the noise generated by passenger car tires. Both community noise and the noise heard by the occupants of the vehicle are considered. Possible noise generation mechanisms, although not well understood, are presented. Areas for future research and development are identified based on gaps in present knowledge.

Lees, R. M., Lovas, F. J., Kirchhoff, W. H., Johnson, D. R., Microwave spectra of molecules of astrophysical interest. III. Methanol, J. Phys. Chem. Ref. Data 2, No. 2, 205-214 (1973).

Key words: Internal rotation; interstellar molecules; methanol; microwave spectra; molecular parameters; radio astronomy; rotational transitions; torsion.

The available data on the microwave spectrum of methanol is critically reviewed for information applicable to radio astronomy. Molecular data such as moments and product of inertia, torsional potential constants, centrifugal distortion and torsion-rotation-interaction constants, dipole moment, and structural parameters are tabulated. Observed rotational transitions are presented for the astronomically interesting isotopic forms of methanol when available. Detailed centrifugal distortion and torsion-rotation interaction calculations have been carried out for the most abundant isotopic form of methanol with transitions tabulated for the frequency range from $500 \mathrm{MHz}$ to $200 \mathrm{GHz}$. Measured transition error limits have been reproduced from the original literature. References are given for all data included.

Leiss, J. E., Future accelerators for photonuclear studies, (Proc. Int. Conf. on Photonuclear Reactions and Applications, Pacific Grove, Calif., Mar. 26-30, 1973), Paper in International Conference on Photonuclear Reactions and Applications, B. L. Berman, Ed., pp. 1241-1248 (Ernest O. Lawrence Livermore Laboratory, University of California, Livermore, Calif., 1973). (Available as CONF-730301 from the National Technical Information Service, Springfield, Va. 22151).

Key words: Electron accelerators; linear accelerators; photonuclear physics; race track microtron; storage rings.

The status of electron accelerator developments and the need for new accelerators in photonuclear studies is discussed. The develop- ment of 100 percent duty cycle accelerators is identified as a major goal. Specific accelerators which would satisfy this goal are identified. The possibility of modifying existing facilities to enhance the application of photon activation analysis is given as an example of ways in which photonuclear applications can be encouraged.

Lide, D. R., Jr., Rossmassler, S. A., Status report on critical compilation of physical chemical data, Annu. Rev. Phys. Chem. 24, 135-158 (1973).

Key words: Compilation; critical evaluation; data; NSRDS; physical chemistry; reference data; status report.

The significance of data evaluation and the importance of sources of reliable reference data are pointed out. A review is provided of major past and present data compilation activities of interest to physical chemists, including early efforts (before 1930); isolated programs in the period 1930-1960; the National Standard Reference Data System; other government and non-government programs; other national programs; and international programs. A rationale and discussion of methodology of data evaluation are presented with brief illustrations. Finally, three types of data sources are listed: systematic publication series, data centers, and recent compendia.

Liebman, J. F., Regularities and relations among ionization potentials of nontransition elements, J. Chem. Educ. 50, No. 12,831-834 (Dec. 1973).

Key words: Atoms; extrapolation; ionization potentials; nontransition elements; semiemphirical rules.

In this paper, we ask "How does the ionization potential vary with increasing atomic number?" and in addition inquire about higher ionization potentials. Five classes of semiempirical procedures are given, utilized and discussed. Two new procedures are introduced and found to be reliable.

Lovas, F. J., Johnson, D. R., Reaction of $\mathbf{B F}_{3}$ with $\mathbf{N H}_{3}$ : Microwave spectrum of $\mathbf{B F}_{2} \mathbf{N H}_{2}, J$. Chem. Phys. 59, No. 5, 2347-2353 (Sept. 1, 1973).

Key words: Aminodifluoroborane; dipole moment; gas-phase reaction; microwave spectrum; molecular structure; rotational transitions.

Microwave spectra assignable to gas phase aminodifluoroborane $\left(\mathrm{BF}_{2} \mathrm{NH}_{2}\right)$ have been detected in the reaction of $\mathrm{BF}_{3}$ with $\mathrm{NH}_{3}$. A centrifugal distortion analysis has been carried out on the species ${ }^{11} \mathrm{BF}_{2}{ }^{14} \mathrm{NH}_{2}$ and ${ }^{10} \mathrm{BF}_{2}{ }^{14} \mathrm{NH}_{2}$. Distortion corrected rotational constants have also been obtained for ${ }^{11} \mathrm{BF}_{2}{ }^{15} \mathrm{NH}_{2},{ }^{10} \mathrm{BF}_{2}{ }^{15} \mathrm{NH}_{2},{ }^{11} \mathrm{BF}_{2}{ }^{14} \mathrm{ND}_{2}$, and ${ }^{10} \mathrm{BF}_{2}{ }^{14} \mathrm{ND}_{2}$. The molecule has been found to be planar with the following geometry: $r_{B-F}=1.325(12) \AA, \quad r_{B-N}=1.402(24) \AA, \quad r_{N-H}=$ $1.0029(18) \AA, \angle F B F=117.9(17)^{\circ}$ and $\angle \mathrm{HNH}=116.94(30)^{\circ}$. The observed dipole moment of $\mathrm{BF}_{2} \mathrm{NH}_{2}$ is $\mu=2.595(30) \mathrm{D}$.

Lowke, J. J., Phelps, A. V., Irwin, B. W., Predicted electron transport coefficients and operating characteristics of $\mathrm{CO}_{2}-\mathbf{N}_{2}$-He laser mixtures, J. Appl. Phys. 44, No. 10, 4664-4671 (Oct. 1973).

Key words: Attachment coefficient; $\mathrm{CO}_{2}$ cross sections; $\mathrm{CO}_{2}$ laser; electron distribution; electron transport; ionization coefficient.

Calculations have been made of transport coefficients of electrons in gas mixtures for ratios $\mathrm{CO}_{2}: \mathrm{N}_{2}: \mathrm{He}$ of $1: 1: 8,1: 2: 3,1: 7: 30$, and $1: 0.25: 3$. New cross sections for $\mathrm{CO}_{2}$ derived from swarm experiments are used together with previously published cross sections for $\mathrm{N}_{2}$ and $\mathrm{He}$. Curves are presented of the predicted electron drift velocity, transverse and longitudinal diffusion coefficients, and ionization and attachment coefficients for $E / N$ values ranging from $10^{-18}$ to $1 \times 10^{-15} \mathrm{~V} \mathrm{~cm}^{2} ; E$ is the electric field strength and $N$ the gas number density. Examples are given of derived distribution functions and comparisons are made with a Maxwellian distribution function. 
The percentage of the input electrical power which excites vibrational processes coupled to the 001 upper laser level of $\mathrm{CO}_{2}$ is given as a function of $E / N$. The maximum efficiency from these calculations increases for increasing ratios of $\mathrm{N}_{2}: \mathrm{CO}_{2}$, because the proportion of energy used to excite the bending and stretching modes of $\mathrm{CO}_{2}$ is then reduced. By assuming a recombination coefficient of $10^{-7} \mathrm{~cm}^{3}$ $\sec ^{-1}$, the operating $E / N$ for self-sustained glow discharges is predicted as a function of current density for various laser mixtures by equating the ionization rate to the attachment and recombination rate.

Martin, W. C., Energy levels of neutral helium ( $\left({ }^{4} \mathrm{He} 1\right)$, J. Phys. Chem. Ref. Data 2, No. 2, 257-265 (1973).

Key words: Atomic energy levels; atomic spectra; autoionization; electron scattering; fine structure; helium; photoionization resonances; photon absorption.

This compilation of all identified levels is based on the most accurate available observations. It includes 48 levels above the HE II $1{ }^{2} \mathrm{~S}$ limit (two-electron excitation).

Mauer, F. A., Hubbard, C. R., Hahn, T. A., Thermal expansion and low temperature phase transition of thallous azide, $J$. Chem. Phys. 59, No. 7, 3770-3776 (Oct. 1, 1973).

Key words: Bond method; phase transition; thallous azide; thermal expansion.

Thallous azide, $\mathrm{TIN}_{3}$, is tetragonal at room temperature. It transforms at $248 \pm 5 \mathrm{~K}$ to a phase that can be indexed on the basis of an orthorhombic cell. Lattice parameters of the tetragonal phase have been determined by the Bond single crystal method at intervals of approximately $25 \mathrm{~K}$ from 248 to $498 \mathrm{~K}$. Single crystals do not survive the transition, so the parameters of the orthorhombic phase were measured by powder diffraction at intervals of $25 \mathrm{~K}$ down to $133 \mathrm{~K}$. Representative parameters, after corrections for the effects of radiation damage, are $a=6.2094 \AA, c=7.3583 \AA$ at $298.2 \mathrm{~K}$ for the tetragonal phase, and $a=8.718 \AA, b=8.766 \AA, c=7.395 \AA$ at $238.2 \mathrm{~K}$ for the orthorhombic. Thermal expansion parameters show anomalies that are believed to be the result of changes in the orientation of azide ions. The linear expansion coefficients, $\alpha_{a}$ and $\alpha_{c}$, for the tetragonal phase are both approximately $5.2 \times 10^{-5} \mathrm{~K}^{-1}$ at the transition. By 486 $\mathrm{K}, \alpha_{c}$ has increased to $21 \times 10^{-5} \mathrm{~K}^{-1}$ and $\alpha_{a}$ has decreased to $-1.2 \times$ $10^{-5} \mathrm{~K}^{-1}$. For the orthorhombic phase $\alpha_{b}$ remains constant at $5.2 \times$ $10^{-5} \mathrm{~K}^{-1}$ while $\alpha_{a}$ increases from $10 \times 10^{-5} \mathrm{~K}^{-1}$ to $22 \times 10^{-5} \mathrm{~K}^{-1}$ and $\alpha_{c}$ decreases from $-1.5 \times 10^{-5} \mathrm{~K}^{-1}$ to $-11 \times 10^{-5} \mathrm{~K}^{-1}$ in the temperature range 150 to $225 \mathrm{~K}$. There does not appear to be a discontinuity in the volume at the transition. The volume expansion coefficient is approximately $17 \times 10^{-5} \mathrm{~K}^{-1}$ for the orthorhombic phase and $15 \times$ $10^{-5} \mathrm{~K}^{-1}$ for the tetragonal.

McAlister, A. J., Dobbyn, R. C., Cuthill, J. R., Williams, M. L., Soft x-ray emission spectra of metallic solids: Critical review of selected systems, J. Phys. Chem. Ref. Data 2, No. 2, 411-426 (1973).

Key words: Alloys; critical review; emission spectra; intermetallic compounds; metals; soft $x$-ray spectra.

Theory and experimental practice in the field of soft $x$-ray emission from metallic solids are briefly reviewed, and measurements on a number of systems are critically evaluated and compared with the results of other techniques and theory, with a view to establishing the pertinence of the soft $x$-ray measurements and indicating specific guidelines for enhancing their value.

McCulloh, K. E., Photoionization of carbon dioxide, J. Chem. Phys. 59, No. 8, 4250-4259 (Oct. 15, 1973).

Key words: Carbon dioxide; $\mathrm{CO}^{+} ; \mathrm{CO}_{2}{ }^{+}$; dissociative ionization; $\mathrm{O}^{+}$; photoionization.

The yields of photoions from $\mathrm{CO}_{2}$ cooled to $150 \mathrm{~K}$ have been mea- sured at a resolution of $0.22 \AA$ for $\mathrm{CO}_{2}{ }^{+}$and $0.4 \AA$ for the $\mathrm{O}^{+}$and $\mathrm{CO}^{+}$ fragments, in the photon energy region extending from onset for each species to approximately $20 \mathrm{eV}$. Most of the observed structure of the molecular ion yield curve recapitulates the well known features of the absorption spectrum, but a number of anomalies are reported. Autoionization peaks at photon energies just above the first molecular ionization limit of $13.773 \pm 0.002 \mathrm{eV}$ do not fit into a pattern characteristic of Rydberg series converging to excited vibrational levels of the ion. Although the Tanaka-Ogawa series and Henning's sharp series can be assigned as $n s$ Rydberg series on the basis of quantum defects, the expected $3 s$ members could not be observed in the present study. The most prominent feature of the $\mathrm{O}^{+}$yield curve is a step at $19.39 \mathrm{eV}$, suggesting that the principal mechanism for production of this fragment is predissociation of $\mathrm{CO}_{2}{ }^{+}\left(C^{2} \Sigma_{g}{ }^{+}\right)$in its ground vibrational state. Completeness of this predissociation is inferred, although the proposed explanation involves doublet-quartet mixing at large bending angles. The structure of the $\mathrm{O}^{+}$yield curve between 19.07 and $19.39 \mathrm{eV}$ suggests that Rydberg states converging to $\mathrm{CO}_{2}{ }^{+}(C)$ also undergo predissociation, with spontaneous ionization, to produce this fragment ion. Evidence pertaining to production of $\mathrm{CO}^{+}$fragments by predissociation of excited vibrational states of $\mathrm{CO}_{2}+(C)$ is also presented.

Mies, F. H., Stimulated emission and population inversion in diatomic bound-continuum transitions, Mol. Phys. 26, No. 5, 1233-1246 (1973).

Key words: Continuum emission; lasers; line shapes; molecular spectroscopy; quantum chemistry; stimulated emission.

Exact expressions are derived for the rate of stimulated emission and the conditions for population inversion in a diatomic bound-continuum transition. The resultant formulae resemble those of a simple, homogeneously broadened, discrete transition with the Lorentzian lineshape replaced by a continuum lineshape, $g^{C}\left(h \nu=E_{v^{\prime}}-\epsilon^{\prime \prime}\right)$, which is approximately equal to the square of the overlap between the initial, emitting, vibrational level $v^{\prime}$ and the final, energy-normalized continuum state $\epsilon^{\prime \prime}$, i.e. $g^{C} \approx\left\langle v^{\prime} \mid \epsilon^{\prime \prime}\right\rangle^{2}$. Using the "reflection method," which is most applicable to a strongly repulsive final state, equations are obtained which allow simple, but accurate, estimation of the pertinent parameters which influence lasing action. Some general conclusions are extracted, and specific results are presented for the stimulated vacuum ultraviolet emission in high pressure Xe.

Moore, L. J., Moody, J. R., Barnes, I. L., Gramlich, J. W., Murphy, T. J., Paulsen, P. J., Shields, W. R., Trace determination of rubidium and strontium in silicate glass standard reference materials, Anal. Chem. 45, No. 14, 2384-2387 (Dec. 1973).

Key words: Isotope dilution; mass spectrometry; rubidium; standards; strontium; trace analysis.

Procedures have been developed for the accurate trace analysis of $\mathrm{Rb}$ and $\mathrm{Sr}$ by mass spectrometric isotope dilution. A new $\mathrm{Sr}$ isotopic assay technique capable of measuring the three abundant $\mathrm{Sr}$ isotopes to $<0.05$ percent (ts) was combined with recently available high purity reagents and absolute standards to produce accurate and reliable analytical techniques. Application of these techniques to the determination of $\mathrm{Rb}$ and $\mathrm{Sr}$ in silicate glass standard reference materials has resulted in accuracies within $<0.25$ percent at the $\mathrm{ppm}(\mu \mathrm{g} / \mathrm{g})$ level and within $<0.6$ percent at the $\mathrm{ppb}(\mathrm{ng} / \mathrm{g})$ level.

Mordfin, L., Robusto, R., Jr., Plastic deformation characteristics of refractory metals above $3000{ }^{\circ} \mathbf{F}$, (Proc. 5th National Society for the Advancement of Material and Process Engineering Technical Conf., Kiamesha Lake, N.Y., Oct. 9-11, 1973), Paper in Materials \& Processes for the 70's 5, 378-393 (SAMPE, National Business Office, Azusa, Calif., Oct. 1973).

Key words: Evaluation; high temperature tests; molybdenum; plastic flow; Poisson ratio; refractory metals; strain hardening; strain rate; stress strain diagrams; tantalum; tensile rro perties. 
Using a photographic strain-measuring technique, exploratory tensile tests were conducted to investigate the plastic behavior of unalloyed molybdenum and tantalum in the hot-working temperature range. Several unusual characteristics were observed, including serrated flow, a negative strain-rate sensitivity and, in one case, considerable strain hardening. These observations indicate a need for further research in this area, before hot-working processes for refractory metals can be made practical.

Morrissey, B. W., McCrackin, F. L., Stromberg, R. R., Determination of distributions in inhomogeneous films, $J$. Colloid Interface Sci. 42, No. 1, 198-200 (Jan. 1973).

Key words: Attenuated total reflection; distributions; ellipsometry; inhomogeneous films.

The distribution of material in an inhomogeneous film is an important parameter in many problems. By representing the inhomogeneous film as a stack of thin homogeneous films, we have developed a method for utilizing concomitant ellipsometric and attenuated total reflection measurements to determine the distribution of films whose thickness can be modified stepwise. We have compared our method to that of Beckman and Harrick, using their data for $\mathrm{SiH}$ impurity within an $\mathrm{SiO}_{2}$ film. For two distributions, an exponential and a Gaussian, our method produced good fits with an accuracy limited only by the incremental thickness used for the calculations. Application of the method of Beckmann and Harrick yielded less accurate results which can also show artificial minima in the distribution.

Nelson, C. A., Steele, D., Symmetry relations among pionization cross sections, Phys. Rev. D 8, No. 9, 2908-2915 (Nov. 1, 1973).

Key words: Inclusive reactions; pionization region; quark model; Regge residue; $\mathrm{SU}(3)$; symmetry relations.

From Mueller's Regge analysis of the pionization region, symmetry relations to order $s^{-1 / 4}$ among invariant cross sections at $x=0$, in which a final pion is observed, are derived. SU(3) and quark universality are assumed to relate the Regge residues at the projectileReggeon vertex. There is good agreement with experiment to $10-15$ percent indicating that the approximate symmetry pattern at nonasymptotic energies is that of total cross sections. The rising of the invariant cross sections to their asymptotic forms as $c-b s^{-1 / 4}$ can be understood in terms of known $j$-plane singularities if the $f$ Pomeron central vertex $g_{f p} p^{\pi+}\left(q_{\perp}^{2}\right)<0$. Symmetry relations valid for final kaons and nucleons and for both the pionization and the targetfragmentation regions are also given.

O'Connell, J. S., Electromagnetic interactions of the fewnucleon systems, Proc. Seminar Electromagnetic Interactions of Nuclei at Low and Medium Energies, Moscow, U.S.S.R., Dec. 11-13, 1972, pp. 299-309 (Dec. 1973).

Key words: Deuterium; electron scattering; helium-3; helium-4; photonuclear; weak interactions.

Recent progress on the photodisintegration electron scattering reactions on the hydrogen and helium isotopes is reviewed. The connection to weak interactions and the effect of meson dynamics on few-nucleon properties and reactions are discussed.

Plummer, E. W., Electronic characterization of submonolayer films, (Proc. Symp. on Monolayer and Submonolayer Helium Films, Stevens Institute, Hoboken, N.J., June 7-8, 1973), Paper in Proceedings of Symposium on Monolayer and Submonolayer Helium Films, J. G. Daunt and E. Lerner, Eds., pp. 157-160 (Plenum Press, New York, N.Y., 1973).

Key words: Electronic characterization; submonolayer films; surfaces; surface spectroscopy.

The complete characterization of a surface or a submonolayer film on a surface must specify the chemical identity of the atoms present, the geometrical or structural arrangement of these atoms, and the distribution in space and energy of electrons around these atoms. Various forms of electron emission spectroscopy are sensitive to the surface region, yet each technique has a different sensitvity and produces a different perturbation of the surface or adsorbed film. Several methods of probing the electronic properties of the surface and submonolayer films are described, and the advantages of each technique are discussed.

Post, M. A., Liquid latex paint analysis, Paint Varnish Prod. Part 1, 63, No. 9, 21-25 (Sept. 1973); Paint Varnish Prod. Part 2, 63, No. 10, 27-38 (Oct. 1973).

Key words: Acrylic; alkyd modified latex paints; deep-tone latex paints; infrared spectroscopy; polyvinyl acetate; styrene-acrylate; vinyl-acrylic; vinyl acetate-dibutyl maleate; vinyl acetateethylene; vinyl acetate-ethyl acrylate; vinyl acetate-2-ethyl-hexyl acrylate; vinyl chloride-acrylate.

The qualitative identification by infrared spectroscopy of latex resins, the quantitative determination of the latex resin and alkyd modifier in alkyd modified latex paints and of the latex resin in unmodified latex paints are discussed. Four procedures for latex resin identification and two methods for quantitative determination of the latex resin are presented. One of the quantitative methods can be used for any latex paint. The other, which is shorter is useful only for paints based on polyvinyl acetate, vinyl acetate-dibutyl maleate and vinyl-acrylic copolymers.

Rasberry, S. D., Heinrich, K. F. J., Calibration for interelement effects in x-ray fluorescence analysis, Anal. Chem. 46, №. 1, 81-89 (Jan. 1974).

Key words: Calibration; empirical calibration; iron-nickelchromium alloys; $x$-ray fluorescence; $x$-ray spectrochemical analysis.

A new empirical method for the calibration of $x$-ray fluorescence analysis in the presence of interelement effects is given. The effects of secondary fluorescence and of absorption are considered separately, with different expressions, in the calibration equation. The new approach is compared with empirical methods previously proposed by other authors, and is accurate and applicable over wide ranges of composition, even when the number of standards available is limited. An alloy system, in which the interelement effects are severe $(\mathrm{Fe}-\mathrm{Ni}$ $\mathrm{Cr}$, over a range of composition from 0 to $100 \%$ ), is studied experimentally; also evaluated are data, previously presented by other authors, for the calcium carbonate-silica system. With reference to 23 chemical determinations, in the two systems, the relative error is \pm 1 percent or less in 13 instances and \pm 4 percent or less in all but two determinations.

Reimer, G. M., Carpenter, B. S., Thorium determination in glasses using fission track technique, Nature 247, 101-102 (Jan. 11, 1974).

Key words: Fast flux; fission track technique; thorium determination; $\mathrm{Th} / \mathrm{U}$ ratio; track excess.

The fission track technique has been applied for the determination of thorium in glasses. Two irradiations are performed. The first is with a thermalized flux to determine the uranium content by fission of ${ }^{235} \mathrm{U}$. The second irradiation is with a fast flux to induce fission of thorium in addition to uranium. By comparing track counts of both irradiations to a uranium standard, the "track excess" of the second irradiation is related to the thorium content. The accuracy is dependent on the $T h / U$ ratio. The uncertainty for the $T h / U$ ratio of 4 is approximately 20 percent and increases as the ratio decreases.

Romanoff, M., Gerhold, W. F., Schwerdtfeger, W. J., Iverson, W. P., Sanderson, B. T., Escalante, E., Watkins, L. L., Alumbaugh, R. L., Protection of steel piles in a natural seawater environment-Part I, (Proc. 3d Int. Congress on Marine Corrosion and 
Fouling, Gaithersburg, Md., Oct. 2-6, 1972), Paper in Proceedings: Third International Congress on Marine Corrosion and Fouling, pp. 103-119 (Northwestern University Press, Evanston, Ill., Oct. 1973).

Key words: Cathodic protection; coating index; corrosion rates; marine environment; polarization techniques; protective coatings; steel piling.

In a joint research effort between the National Bureau of Standards, the U.S. Army Corps of Engineers, and the U.S. Naval Civil Engineering Laboratory, the corrosion behavior of protected carbon and low alloy steel piling in seawater is being investigated. Nine-three " $\mathrm{H}$ " and pipe pile specimens, 35 feet long, were jetted into the Atlantic Ocean floor off the coast of Dam Neck, Va. The results of this study, which will take about 15 years to complete, will demonstrate which of the systems tested are best for protecting steel piles in seawater. Many types of protective methods are included in the investigation consisting of coating systems (coal-tar epoxy, hot-dip zinc, flamesprayed aluminum and zinc, zinc-rich paints, epoxies, etc.), cathodic protection by zinc and aluminum sacrificial anodes, and combinations of coatings and cathodic protection. At one-year intervals, polarization measurements and visual observations are made on the piles to determine the effectiveness of the coating systems and to measure the rates of corrosion. Potentials of cathodically protected piles are also measured. These data will be correlated with physical determinations made on the piles when they are removed from exposure. The first removal of one set of piles (31 in number) is scheduled for October 1972, after exposure for approximately 5 years.

Schooley, J. F., Superconductive transition in cadmium, J. Low. Temp. Phys. 12, Nos. 5/6, 421-437 (Mar. 14, 1973).

Key words: Cryogenics; pure cadmium; reproducibility; superconductivity; thermometric fixed point; transition temperature; transition widths.

Mutual inductance measurements of the superconductive transitions occurring in single-crystal and polycrystalline cadmium samples in magnetic fields of $0-10^{-4} \mathrm{~T}(0-1 \mathrm{G})$ are presented. The temperature at which the zero-field superconductive transition midpoints occur appears to be constant within $\pm 0.2 \mathrm{mK}$ for transitions narrower than $2 \mathrm{mK}$, but $\mathrm{T}_{c}$ increases for broader transitions. The transitions exhibited both narrowing and hysteresis, the latter perhaps due to supercooling, in fields of a few tenths of a gauss. $\mathrm{T}_{c}$ has been measured as $0.515 \pm 0.002{ }_{5} \mathrm{~K}$ on the $\mathrm{T}_{62}$ temperature scale.

Simmons, G. L., Eisenhauer, C., Moments method calculations of neutron distributions in concrete, Nucl. Sci. Eng. 53, 197 219 (1974).

Key words: Concrete; function fitting; moments; neutron transport; reactor shields; shielding.

The moments method is applied to the problem of calculating neutron distributions in an infinite medium. Several comparisons are given of these results with similar data calculated by the discrete ordinates method. New calculations are presented on the distribution of doses from neutrons, originating in a plane-slant fission source and incident, at various angles, on concrete utilized in radiation measurements at the Tower Shielding Facility of the Oak Ridge National Laboratory (TSF concrete). For a given set of neutron cross sections, these results give reliable estimates of the dose distribution at deep penetrations, i.e., attenuation of six orders of magnitude or more. Functional representations of the distributions are included in order to facilitate the use of the data in shield design calculations.

Smith, E. W., Cooper, J., Chappell, W. R., Dillon, T., An impact theory for Doppler and pressure broadening-I. General theory, J. Quant. Spectrosc. Radiat. Transfer 11, 1547-1565 (1971).

Key words: Molecular collisions; scattering theory; spectral line widths.
A quantum-mechanical impact theory for the combined effects of Doppler and pressure broadening is developed from quantum radiation theory. The results are compared with other semiclassical theories and certain simplifying approximations relevant to cases of experimental and theoretical interest are discussed.

Smith, E. W., Cooper, J., Chappell, W. R., Dillon, T., An impact theory for Doppler and pressure broadening-II. Atomic and molecular systems, J. Quant. Spectrosc. Radiat. Transfer 11, 1567-1576 (1971).

Key words: Molecular collisions; scattering theory; spectral line widths.

A semiclassical theory for Doppler and pressure broadening in neutral gases is derived as a limiting case of a more general quantum mechanical theory. This theory is compared with other semiclassical theories and methods of calculation are discussed.

Smith, E. W., Cooper, J., Roszman, L. J., An analysis of the unified and scalar additivity theories of spectral line broadening, J. Quant. Spectrosc. Radiat. Transfer 13, 1523-1538 (1973).

Key words: Relaxation theory; scalar additivity theory; spectral line broadening; unified theory.

A new derivation of both unified and scalar additivity theories is given. This derivation concentrates on their regions of validity and certain key differences are analyzed in detail.

Smith, E. W., Cooper, J., Vidal, C. R., Comments on the validity of the unified classical path theory of Stark broadening, $J$. Phys. B 5, L33-L35 (1972).

Key words: Electron gas; Stark broadening; unified theory.

In a recent paper by Frisch and Brissaud certain aspects of the unified classical path theory for Stark broadening are criticized; since we feel that their results could be misleading, we offer some comments on their paper.

Smith, M. W., Wiese, W. L., Atomic transition probabilities for forbidden lines of the iron group elements, (A critical data compilation for selected lines), J. Phys. Chem. Ref. Data 2, No. 1, 85-120 (1973).

Key words: Chromium; cobalt; forbidden transitions; iron; manganese; nickel; transition probabilities; vanadium.

Atomic transition probabilities for about 750 forbidden spectral lines for elements of the iron group, specifically $\mathrm{V}, \mathrm{Cr}, \mathrm{Mn}, \mathrm{Fe}, \mathrm{Co}$, and $\mathrm{Ni}$, have been critically evaluated and compiled using all available literature sources. The selection of the spectra and elements has been made primarily according to their astrophysical importance. The data are presented in separate tables for each element and stage of ionization and for each ion the data are arranged according to multiplets. For each line within a multiplet the transition probability for spontaneous emission is listed along with the standard spectroscopic designation, the wavelength, the statistical weights, and the energy levels of the upper and lower states. In addition, the estimated accuracy and the source are indicated. In short introductions which precede the tables for each ion the main justifications for the choice of the adopted data and for the accuracy rating are discussed. A general introduction contains a detailed discussion of the critical factors entering into the calculations. It also includes detailed comparisons of calculated data with astrophysical observations and a few laboratory results, which serve as a valuable indication for the validity of the estimated accuracies.

Soulen, R. J., Jr., Schooley, J. F., Evans, G. A., Jr., Simple instrumentation for the inductive detection of superconductivity, Rev. Sci. Instrum. 44, No. 10, 1537-1538 (Oct. 1973).

Key words: ac susceptibility; superconductivity; temperature; thermometric fixed point. 
A circuit is described which can be used to detect the superconductive transitions of several elements used as thermometric fixed points. The circuit is found to perform as well as much more elaborate mutual inductance bridges previously used for this research. Details for construction and operation for the circuit are given.

Stern, K. H., The effect of anions on sodium-determined glass membrane potentials in molten salts, J. Phys. Chem. 74, No. 6, 1329-1337 (Mar. 19, 1970).

Key words: Glass electrode; glass membrane potential; molten salts.

The effect of changing anion composition on the sodium-determined glass membrane potential was studied using the molten salt concentration cell

\section{Ag/AgCl, AgA, $\mathrm{Na}^{+} /$fused silica/AgCl, $\mathrm{AgA}, \mathrm{Na}^{+} / \mathrm{Ag}$ or Pyrex} I II

for low concentrations of $\mathrm{Na}^{+}$, and $\mathrm{A}=\mathrm{NO}_{3}{ }^{-}, \mathrm{SO}_{4}{ }^{2-}, \mathrm{CrO}_{4}{ }^{2-}, \mathrm{PO}_{4}{ }^{3-}$. For all of these anions the ion-exchange selectivity constant increases in a regular manner with increasing oxyanion concentration. Since the cation mobility ratio in the glass is unaffected by changing melt composition, the ion-exchange equilibrium constant similarly increases. These results are accounted for in terms of Eisenman's selectivity theory and the double layer at the glass-melt interface.

Stern, K. H., The effect of cations on the thermal decomposition of salts with oxyanions. A semi-empirical correlation, J. Chem. Educ. 46, No. 10,645-649 (Oct. 1969).

Key words: Inorganic oxyanions; thermal decomposition; thermodynamics.

Decomposition reaction enthalpies of sulfates, carbonates, nitrates and phosphates to the respective oxides are linear functions of the cation radius/electronegativity $(r / S)$ ratio. Alkali metal salts are more stable than predicted by this relation since their oxides have the antifluorite structure which is less stable than the $\mathrm{NaCl}$ structure in which most of the other oxides crystallize.

Swanson, N., Cooper, J. W., Kuyatt, C. E., Resonant structure in near-threshold electron excitation of krypton, Phys. Rev. A 8, No. 4, 1825-1834 (Oct. 1973).

Key words: Electron excitation; high resolution; krypton; resonance.

By using a monochromator-analyzer combination, electron-excitation functions of the lowest-lying electronic states of krypton have been obtained at a scattering angle of $45^{\circ}$ in the near-threshold region $(9-14 \mathrm{eV})$. All excitation functions display a complex resonant structure. Additional data have been obtained on elastic scattering at $45^{\circ}$ to provide further information on the resonances. In addition to the $4 p^{5} 5 s^{2} J=3 / 2,1 / 2$ resonance doublet, a number of narrow resonances appear below about $12 \mathrm{eV}$ in both the excitation data and elastic scattering which correlate in energy with recent measurements on transmission by Sanche and Schulz. Broad resonant structure is found in a number of the excitation curves and the excitation process in the near-threshold region appears to be dominated by resonant effects. An analysis of the elastic-scattering data on the $4 p^{5} 5 s^{2}$ doublet is presented and resonance parameters obtained compared with theory. A comparison of the narrow resonant structure data with optical absorption data $\mathrm{Rb}$ I obtained by Beutler indicates that the narrow resonances in the $10.5-12 \cdot \mathrm{eV}$ region are probably due to levels of the $4 p^{5} 5 s 4 d$ configuration.

Taylor, P. O., Dunn, G. H., Absolute cross sections and polarization for electron-impact excitation of the $K$ and $H$ resonance lines of the $\mathbf{C a}^{+}$ion, Phys. Rev. A 8, No. 5, 2304-2321 (Nov. 1973).

Key words: Ca II; electron impact; excitation cross sections; polarization; resonance lines.
Crossed beams of electrons and $\mathrm{Ca}^{+}$ions have been used to measure absolute cross sections for electron-impact excitation of the resonance $K$ and $H$ lines of Ca II at 3934 and $3968 \AA$, respectively. Polarization fractions of the light were also measured. The cross sections presented are absolute in the sense that all measurables including photon flux, have been compared to relevant standards. The cross section for excitation of the $K$ line is observed to have a value of about $(18 \pm 2) \pi a_{0}{ }^{2}$ at the $3.15-\mathrm{eV}$ threshold, and to decrease to a magnitude of $(1.5 \pm 13) \pi a_{0}{ }^{2}$ at $700-\mathrm{eV}$ electron energy. Experimental uncertainties have been presented at the 98 percent confidence level, typically three standard deviations of random fluctuations combined in quadrature with the systematic uncertainties. The experimental results for both the $K$ and $H$ emissions are in agreement at $350 \mathrm{eV}$ with the Coulomb distorted-wave calculation of Burgess and Sheorey but lie about 35 percent below the low-energy three-state closecoupling calculations of Burke and Moores. The ratio of the cross sections for the $K$ and $H$ emission is found to be 2.0 at all energies. Detailed study of the cross section at low energies demonstrates the expected finite value at threshold (within the accuracy allowed by the electron energy spread of $0.3 \mathrm{eV}$ ), and does not indicate the presence of a large (greater than 5\%) contribution from cascade. Structure in the $K$ cross section about $2 \mathrm{eV}$ above threshold suggests interactions with autoionizing levels of Ca I, presumably belonging to the $5 \mathrm{snl}$ or $4 d n l$ series. The polarization fraction at low energy is about 25 percent higher than the calculation of Saraph which is based on the Burke and Moores close-coupling calculation.

Thomas, R. N., Gebbie, K. B., Theory of stellar atmospheres, Trans. Int. Astron. Union 15A, 537-569 (1973).

Key words: Stellar atmospheres.

This report has been prepared by the President in collaboration with the Secretary of the Commission. It is based on (1) material supplied by those members and associates of the Commission who responded to requests made in our circulars, (2) a bibliographical search intended to supplement the above material, (3) discussions with other interested persons, and (4) our own knowledge and impressions of the activity within the province of the Commission over the last three years. The report is divided into three parts. Part A is a scientific review aimed not at a comprehensive summary of all work but at a selective review of that which has, in our opinion, introduced some significant change in our concept of a stellar atmosphere or in the likely direction of future developments. Part B is a bibliography. It is this part of the report that is intended to provide an exhaustive summary of work done in the field over the last three years. To authors of those papers we have inadvertently omitted, we offer our apologies: neither were they sent to us nor did we locate them ourselves. Finally, Part C is an outline of the aims and activities of the Commission.

The decision to write the entire report ourselves, rather than delegate specific sections to other people, was aimed at providing a more coherent approach to the subject as a whole. Clearly, this represents only one of many possible approaches, and the form of the report is highly individual. The choice of what to include without encroaching on the fields of other commissions has become increasingly difficult. No longer can Commission 36 confine itself to theoretical models of stellar atmospheres. Empirical analyses that reveal inconsistencies in our theoretical assumptions must also be included, as must some consideration of solar phenomena, which are now recog. nized as being relevant to a wide variety of stars. Reference must also be made to those results of physics that are immediately applicable to the theory of stellar atmospheres. Inevitably, the selection has to some extent been arbitrary.

Thomas, R. N., Suggested interpretation of the correlations in intensity fluctuations in the lines $\mathrm{Ca}$ II $\mathrm{H}$ and $\mathrm{K}$, magnesium b, and hydrogen H $\boldsymbol{\beta}$, Solar Phys. 27, 303-304 (Dec. 1972).

Key words: Intensity fluctuations; solar spectral lines. 
In the preceding note, Evans and Catalano have found interesting behavior in the correlation between intensity fluctuations in the continuum and in the lines $\mathrm{H}$ and $\mathrm{K}$ of $\mathrm{Ca} \mathrm{II}, \mathrm{bl}$ and $\mathrm{b} 2$ of $\mathrm{MgI}$, and hydrogen $\mathrm{H} \beta$. In the first four lines, the correlation drops smoothly from $\sim 0.9$ near the continuum to negative values; followed by a rise to about zero at line center. For $\mathrm{H}$, the correlation is never negative, reaching zero at about $0.25 \AA$.

We suggest that this behavior reflects a combination of effects. First the source-sink terms in the source-functions depend on dif ferent physical parameters in the two sets of lines. In addition, the line center regions are dominated by transfer effects at the top of the atmosphere.

Tilford, S. G., Simmons, J. D., Atlas of the observed absorption spectrum of carbon monoxide between 1060 and $1900 \AA$, J. Phys. Chem. Ref. Data 1, No. 1, 147-187 (1972).

Key words: Absorption spectra; carbon monoxide; electronic transitions; identification atlas; potential energy curves; rotational constants; ultraviolet; vibrational constants.

This atlas summarizes the results of a recent investigation of the carbon monoxide absorption spectrum between 1060 and $1900 \AA$. Twelve electronic transitions are observed in this region; four electric dipole allowed electric transitions from the ground state $\mathrm{X}^{1} \Sigma^{+}$to the $\mathrm{A}^{1} \Pi, \mathrm{B}^{1} \Sigma^{+}, \mathrm{C}^{1} \Sigma^{+}$, and $\mathrm{E}^{1} \Pi$ states, and eight forbidden transitions to the $a^{\prime}{ }^{3} \Sigma^{+}, e^{3} \Sigma^{-}, a^{3} \Pi, \mathrm{D}^{1} \Delta, d^{3} \Delta_{i}, \mathrm{I}^{1} \Sigma^{-}, j^{3} \Sigma^{+}$, and $c^{3} \Pi$ states. The following items are presented in the atlas: (1) A photograph of the spectrum with band assignments; (2) a table of band head measurements and assignments arranged by wavelength; (3) a summary of the spectroscopic constants and potential curve for each electronic state; (4) a line list, arranged by wavelength, of the observed rotational lines of the allowed transitions.

Tschiegg, C. E., Greenspan, M., Helmholtz resonators as sonic bubble chambers?, J. Acoust. Soc. Amer. 54, No. 4, 1112-1113 (oct. 1973).

Key words: Bubble chamber; Helmholtz resonators; rapidcycling bubble chamber; sonic bubble chamber.

It has been found possible to develop alternating pressures of up to $10 \mathrm{~atm}$ in liquid-filled Helmholtz resonators. Some advantages and disadvantages of the construction of a rapid-cycling bubble chamber along such lines are discussed.

Vidal, C. R., Cooper, J., Smith, E. W., Hydrogen Stark-broadening tables, Astrophys. J. Suppl. Ser. 25, No. 214, 37-135 (Jan. 1973).

Key words: Stark broadening of hydrogen.

Tables of Stark broadening of the first four Lyman lines and the first four Balmer lines of hydrogen are presented. They are based on a recently developed "unified theory" of line broadening which generates normalized profiles covering the entire profile from the impact limit in the line center to the quasi-static limit in the line wings. The tables are presented in a convenient form for accurate numerical interpolation.

Vidal, C. R., Spectroscopic observations of subsonic and sonic vapor flow inside an open-ended heat pipe, J. Appl. Phys. 44, No. 5, 2225-2232 (May 1973).

Key words: Heat pipe oven; resonance fluorescence spectra; sonic flow.

Spectroscopic measurements of the vapor flow velocities inside a heat-pipe oven have been performed as a function of pressure, heater power, and radial position inside the pipe. For this purpose the relative intensity of the collision-induced satellite lines in laser-induced resonance fluorescence spectra of the ${ }^{7} \mathrm{Li}_{2}$ molecule has been em- ployed. A one-dimensional flow model is presented which determines the vapor parameters as a function of position along the pipe. It predicts the onset of the sonic flow which has been verified experimentally. A criterion is derived from which the parameters of the vapor can be obtained from the ideal gas relation, neglecting velocity-dependent terms.

Weisman, I. D., Bennett, L. H., Maxwell, L. R., Sr., In vivo NMR relaxation studies of tumors, IEEE Trans. Magn. MAG-9, №. 3, 454-456 (Sept. 1973).

Key words: In vivo; melanoma; nuclear magnetic resonance; spin-lattice relaxation; spin-spin relaxation; tumor.

Pulsed nuclear magnetic resonance has been used to differentiate between normal mouse tail tissue and a malignant transplanted melanoma S91 located on the tail of a live mouse. Measurements of proton spin-lattice and spin-spin relaxation serve to detect and monitor the tumor growth. The mature tumor exhibits a spin-lattice relaxation time $T_{1}$ of $\sim 0.7-0.8 \mathrm{~s}$ contrasting with the corresponding normal tail tissue $T_{1}$ of half this value. On the other hand spin-spin relaxation in normal tissue cannot be characterized by a single relaxation time $T_{2}$. The corresponding relaxation in a mature tumor is found to be closer to a single exponential but still requires at least two superimposed exponential decays.

Weisman, I. D., Swartzendruber, L. J., Bennett, L. H., Nuclear resonances in metals: Nuclear magnetic resonance and Mössbauer effect, Chapter 9 in Techniques in Metals Research, E. Passaglia and E. Bunshah, Eds., 6, Part 2, 165-504 (John Wiley and Sons, Inc., New York, N.Y., 1973).

Key words: Experimental techniques; ferromagnetic nuclear resonance; metallurgy; Mössbauer effect; nuclear magnetic resonance; pure quadrupole resonance.

It is the purpose of this chapter to review nuclear magnetic resonance, nuclear quadrupole resonance, ferromagnetic nuclear resonance and the Mössbauer effect in metals, alloys and intermetallic compounds. The emphasis is on the technique of measurement, and includes only such theory as is deemed essential to understand the purpose of the measurement, its limitations, the sample preparation required, and when a particular kind of measurement is most appropriate.

Wiederhorn, S. M., Hockey, B. J., Roberts, D. E., Effect of temperature on the fracture of sapphire, Phil. Mag. 28, No. 4, 783-796 (Oct. 1973).

Key words: Alumina; crack growth; critical stress intensity factor; fracture; plastic deformation; sapphire; strength; transmission electron microscopy.

At low temperatures, metastable crack growth dictates the environment free strength of sapphire. Plastic deformation by dislocation motion or twin formation and growth plays no role in the fracture process at temperatures below $400{ }^{\circ} \mathrm{C}$. These conclusions are supported both by crack growth studies and critical stress intensity factor measurements on sapphire crystals, and by transmission electron microscopy studies of arrested cracks in sapphire and alumina.

Wiese, W. L., Arc plasmas as radiation standards in the vacuum ultraviolet, (Proc. VI Yugoslav Symp. and Summer School on the Physics of Ionized Gases, Miljevac by Split, Yugoslavia, July 16-21, 1972), Paper in Physics of Ionized Gases, M. V. Kurepa, Ed., pp. 597-625 (Institute of Physics, Beograd, Yugoslavia, 1972).

Key words: Hydrogen arc plasma; radiation standard; radiometric calibrations; vacuum ultraviolet.

The principle of using arc plasmas as radiation standards in the 
vacuum ultraviolet is described, and it is shown that a hydrogen arc plasma has particularly suitable properties due to the fact that its atomic radiation constants are exactly known. The calibration work with a hydrogen arc plasma at NBS is discussed, and preliminary results with this recently established facility are presented.

Yates, J. T., Jr., Madey, T. E., Rook, H. L., Wear of English monumental brasses caused by brass rubbing, Nature 243, No. 5407, 422-424 (June 15, 1973).

Key words: Monumental brasses; neutron activation; preservation of historical objects; wear.

Measurements of the wear of English monumental brasses during brass rubbing have been made using neutron activation analysis. The median rate of wear as determined from twenty-six measurements corresponds to an average thickness of $1.8 \times 10^{-8} \mathrm{~cm}$ of brass removed per rubbing.

Young, K. F., Frederikse, H. P. R., Compilation of the static dielectric constant of inorganic solids, J. Phys. Chem. Ref. Data 2, No. 2,313-409 (1973).

Key words: Dielectric loss (tangent); permittivity; static dielectric constant, frequency dependence of, temperature dependence of, pressure dependence of.

This monograph contains values of the static dielectric constant of more than 300 inorganic solids. The temperature and frequency of the measurements are listed and the magnitude of the loss tangent is indicated if known. For ninety materials-including most ferroelectrics and antiferroelectrics and several oxides and halides-additional information is presented in the form of graphs depicting the temperature dependence of the dielectric constant. In a few cases the frequency and pressure dependences are also shown. The basic principles and formulas pertinent to the field of dielectrics are reviewed in a short introduction. This part also mentions several measuring techniques and indicates the criteria used for data selection. 